ANL-6079

Instruments

(TID-4500, 15th Ed.)

AEC Research and

Development Report

\author{
ARGONNE NATIONAL LABORATORY \\ P. O. Box 299 \\ Lemont, Illinois
}

\title{
MANIPULATOR CABLE \\ WITH CONSTANT STRESS
}

by

John H. Grimson

\author{
A thesis \\ submitted to the Graduate School \\ in partial fulfillment of the requirements \\ for the degree \\ Master of Science \\ Department of Mechanical Engineering \\ Northwestern University, Evanston, Illinois
}

November, 1959

\footnotetext{
Operated by The University of Chicago under

Contract $W-31-109$-eng-38
} 


\section{DISCLAIMER}

This report was prepared as an account of work sponsored by an agency of the United States Government. Neither the United States Government nor any agency Thereof, nor any of their employees, makes any warranty, express or implied, or assumes any legal liability or responsibility for the accuracy, completeness, or usefulness of any information, apparatus, product, or process disclosed, or represents that its use would not infringe privately owned rights. Reference herein to any specific commercial product, process, or service by trade name, trademark, manufacturer, or otherwise does not necessarily constitute or imply its endorsement, recommendation, or favoring by the United States Government or any agency thereof. The views and opinions of authors expressed herein do not necessarily state or reflect those of the United States Government or any agency thereof. 


\section{DISCLAIMER}

Portions of this document may be illegible in electronic image products. Images are produced from the best available original document. 


\section{TABLE OF CONTENTS}

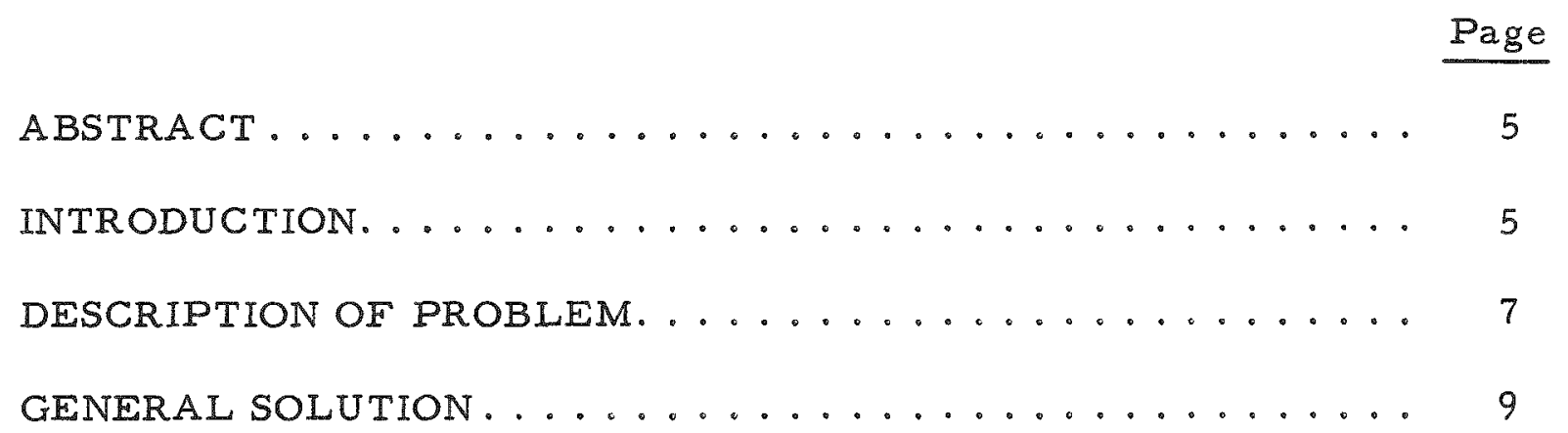

Particular Solution A (Pulley Pitch Line Tangent to

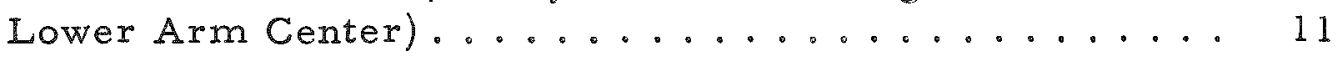

Results (Tabular and Graphical) ............. 15

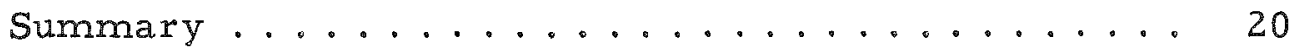

Particular Solution B (Pulley Center Moving on the Arc of a Circle $\ldots \ldots \ldots \ldots . \ldots \ldots 20$

Results (Tabular and Graphical) ........... 24

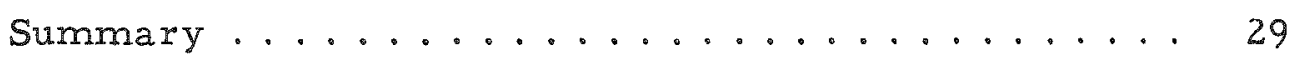

DESIGN OF MANIPULATOR MECHANISM ........... 30

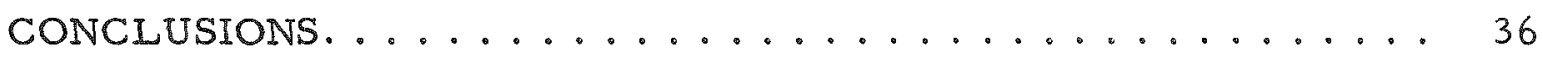

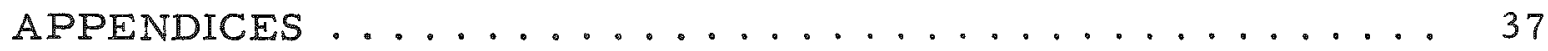

Bell $L_{1}$ Computer System.................. 37

Program for Particular Solution A ............... 39

Program for Particular Solution B ............ 41

BIBLIOGRAPHY ....................... 43

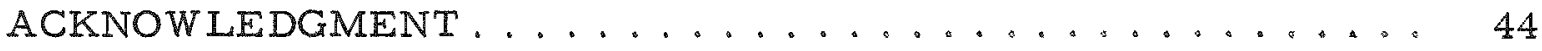




\section{LIST OF FIGURES}

No.

Title

Page

1. Mechanical Manipulator..................6 6

2. Electronic Manipulator .................. 7

3. Manipulator Geometry................. 8

4. Pulley Pitch Line Tangent to Arm Center Line ........ I I

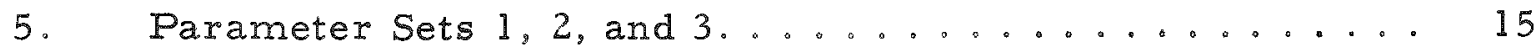

6. Parameter $\operatorname{Sets} 4,5$, and $6 \ldots \ldots 16$

7. Parameter Sets 7 and $9 \ldots \ldots \ldots$

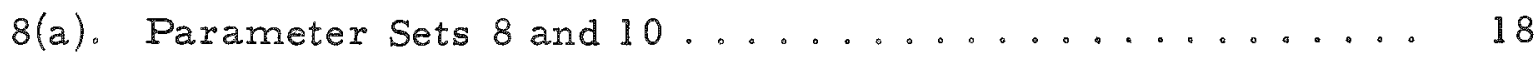

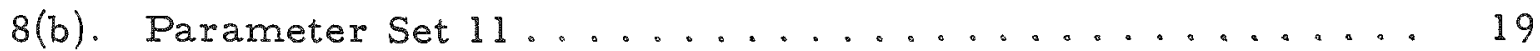

9. Pulley Center Moving on the Arc of a Circle ......... 21

10. Single Link Relationships................ 23

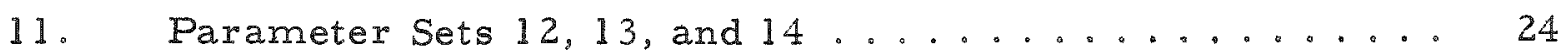

12. Parameter Sets 15,16 , and $17 \ldots \ldots 25$

13. Parameter Sets 18,19 , and $20 \ldots \ldots 26$

14. Parameter Sets 21 and $22 \ldots \ldots 27$

15. Parameter Sets 23 and $24 \ldots \ldots 28$

16. Single Link ...................... 34

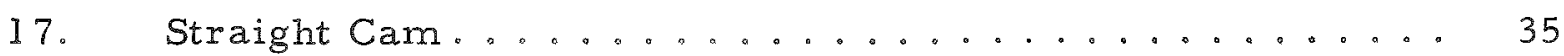

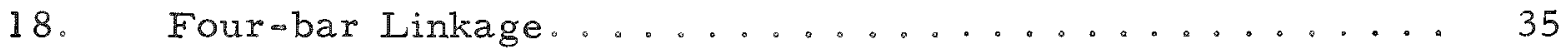




\section{LIST OF TABLES}

No.

Title

Page

I. Parameters for $X=R \csc \alpha+Y \cot \alpha \ldots \ldots 14$

II. Parameter Set $\ldots \ldots \ldots \ldots \ldots$

III. Parameter Set 2................ 15

IV. Parameter Set $\ldots \ldots \ldots \ldots$

V. Parameter Set $4 \ldots \ldots \ldots \ldots$

VI. Parameter Set $\ldots \ldots \ldots \ldots \ldots$

VII $\quad$ Parameter Set $6 \ldots \ldots \ldots 16$

VIII. Parameter Set $\ldots \ldots \ldots \ldots 17$

IX. Parameter Set $\ldots \ldots \ldots \ldots \ldots$

X. Parameter Set $\ldots \ldots \ldots \ldots \ldots \ldots$

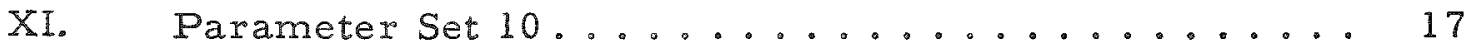

XII. Parameter Set 11................... 19

XII. Parameters for $\mathrm{X}=\sqrt{2.25 R^{2}-(\mathrm{Y}+0.5 \mathrm{R})^{2}} \ldots \ldots 22$

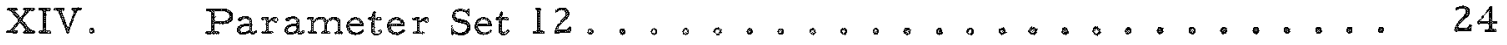

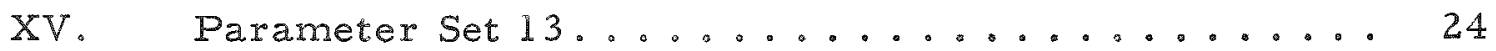

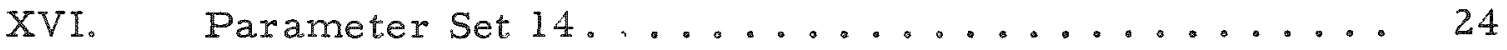

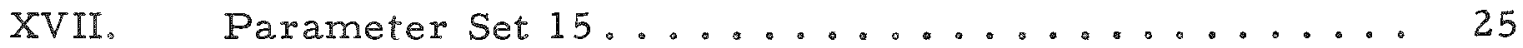

XVIII. Parameter Set $16 \ldots \ldots \ldots \ldots \ldots$

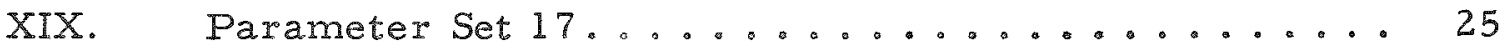

XX. Parameter Set $18 \ldots \ldots \ldots \ldots$

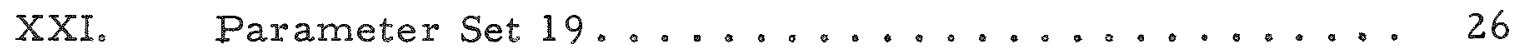

XXII. Parameter Set $20 \ldots \ldots \ldots \ldots$

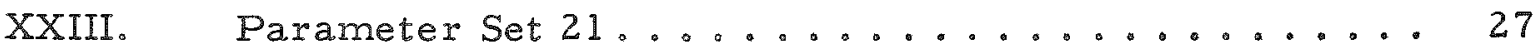

XXIV。 Parameter Set $22 \ldots \ldots \ldots \ldots \ldots$

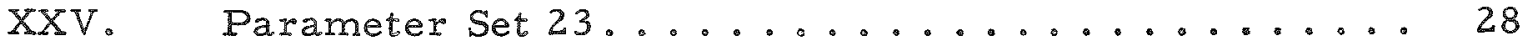

XXVI. Parameter Set $24 \ldots \ldots \ldots \ldots \ldots$

XXVII. Load Capacities and Relative Deflections of Cables

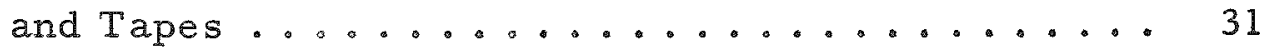

XXVIII. Percentages of Ultimate Load for Cables and Tapes. . . 33

XXIX. Summary of Operation Codes .............. 38 


\title{
MANIPULATOR CABLE \\ WITH CONSTANT STRESS
}

John H. Grimson

\begin{abstract}
A manipulator or mechanical arm involves an upper and a lower arm, as it were, with a variable angle between them. Cables used to transmit motion and force from the upper to the lower arms pass over a pulley at the joint or elbow. A pulley, axially fixed with respect to the joint, imposes a change in length of the cable as the angle between the arms varies. Manipulation design requires a cable of constant length during this variation; this constant length may be achieved by guiding the center of the pulley along the proper path. Two acceptable solutions were obtained in terms of four variables, viz., the lengths of each arm, the radius of the pulley, and the angle between the arms. One solution moved the pulley center along a straight line with respect to the lower arm. The other solution moved the pulley center along a circular arc with respect to the upper arm. Practical and economical mechanisms based on these solutions were investigated for use in manipulator design.
\end{abstract}

\section{INTRODUCTION}

With man's exploration of the atom, methods of handling radioactive elements remotely became a necessity. This need produced a mechanical arm called a master-slave manipulator. The earliest manipulators, and subsequent mechanical manipulators, consisted of two vertical arms connected directly by tapes or cables through a horizontal member. The vertical arm within the radioactive area was called the slave, while the arm which the operator actually works was called the master. Manipulator design must acknowledge the basic requirements of minimum friction, inertia and backlash throughout the complete system.

These mechanical manipulators were sufficient for the earlier handling problems involving gamma radiation only. Containment of gamma radioactivity has been achieved through the construction of shielded facilities, usually of a dense concrete. Escape of particulate matter was controlled by negative air pressure within the facility, which produced inward air velocities through cracks or openings in excess of $100 \mathrm{fpm}$. Alpha radioactivity has been handled in tightly sealed glove boxes. Combining these two types of activity, new problems have become evident in the remote-handling field. 
Gamma facilities must be made both gas - and particulate-tight as a first requirement for containment of alpha activity. Sealing of movable cables in a horizontal tube becomes a difficult problem. In addition, facilities containing both types of radiation are growing in size. These problems have led to the development of "electronically controlled" manipulators. These manipulators have the master and slave arms connected by only a multiple-conductor electrical cable, which may be sealed more easily than moving mechanical cables. An electrically connected manipulator also allows greater coverage of the slave area when coupled with some type of vehicle.

In spite of the advantages noted, certain difficulties appear. One of these is the problem of a mechanical cable of constant length. Fig. 1 shows how the completely mechanical manipulator does this inherently. Fig. I(a) shows the normal position, whereas Fig. l(b) shows a decrease in the angle $\alpha$. The inherent compensation during this decrease is due to the fact that as the cable unwraps from pulley $A$, an equal amount wraps onto pulley $B$.

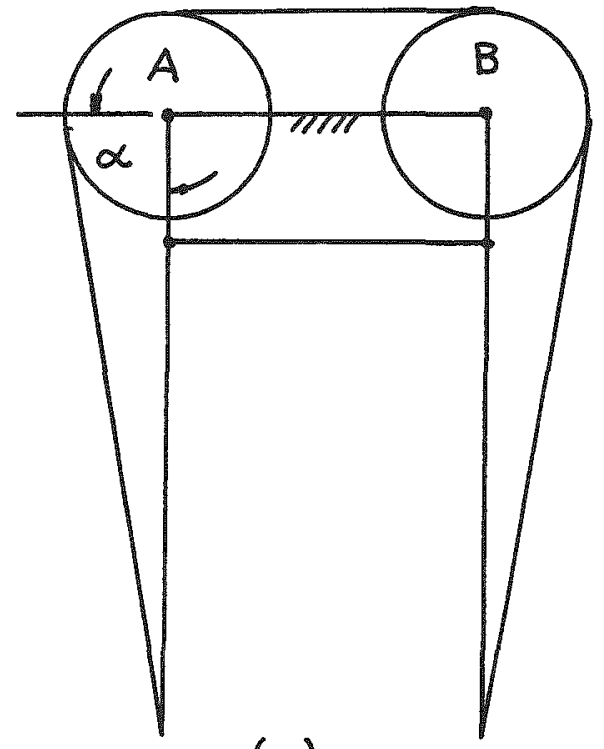

(a)

FIG. I

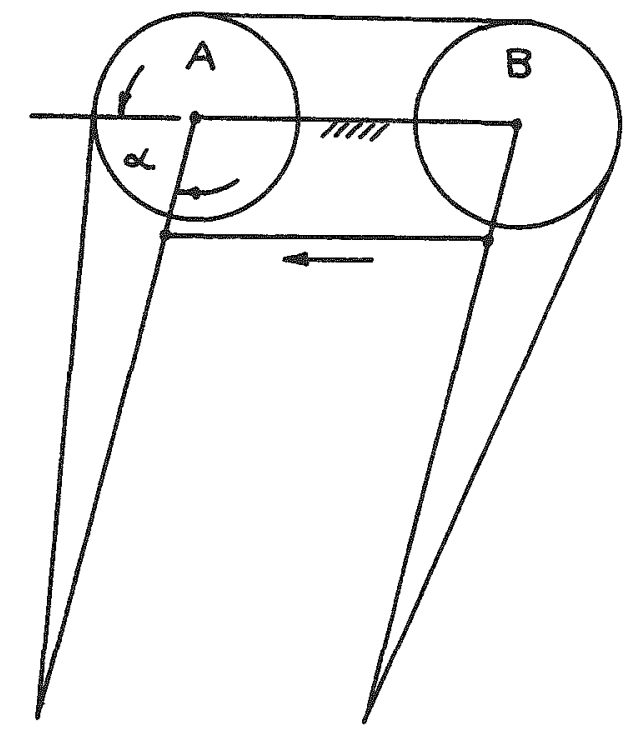

(b)

Fig. 2 shows how an electronic manipulator differs. Fig. $2(a)$ shows the normal position, whereas Fig. 2(b) shows a decrease in the angle $\alpha$. In this case, as $\alpha$ decreases the amount of wrap on pulley $B$ increases, calling for an increase in cable length to maintain a constant force. If the cable length is to remain constant, the pulley center must be moved. Determining the proper path to be followed by the center of the pulley to give a constant cable length has proved to be a very laborious job on the present electronic manipulators. 


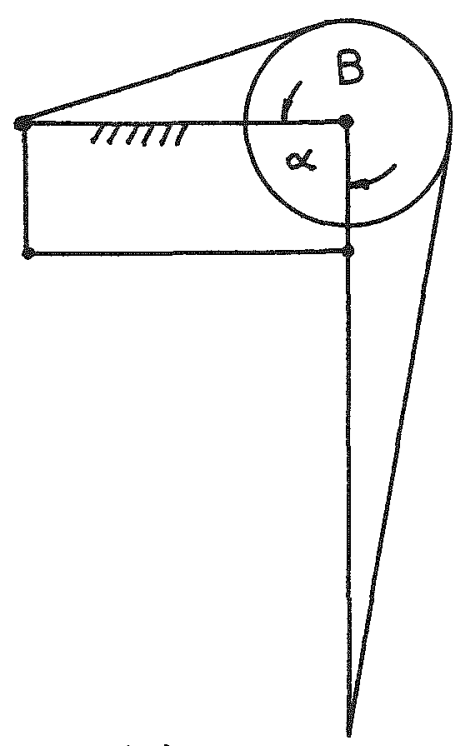

(a)

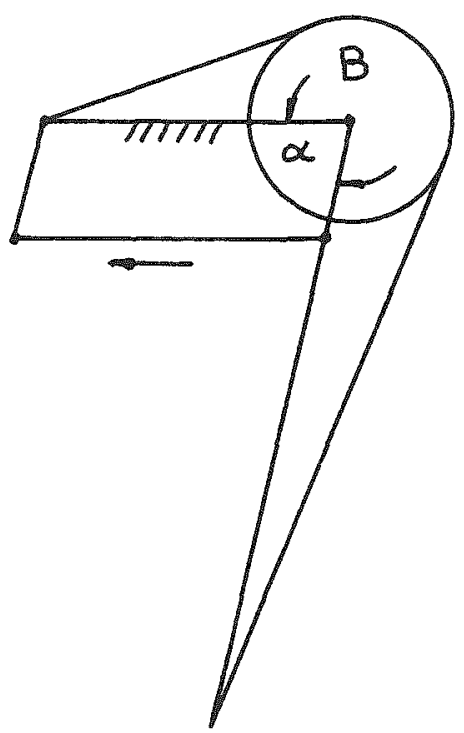

(b)

\section{Fig. 2 Electronic Manipulator}

The purpose of this paper was to find a general solution for the pulley path for any manipulator, thus eliminating the need for a new investigation for each new model with different parameters.

\section{DESCRIPTION OF PROBLEM}

The problem can best be described by means of a schematic diagram (see Fig. 3). The symbols are defined as follows:

$L_{1} \quad=$ length of upper or fixed manipulator arm, in.

$\mathrm{L}_{2} \quad=$ length of lower or moving manipulator arm, in.

$\mathrm{R} \quad=$ pitch radius of the pulley, in.

C = length of cable, in.

$\alpha \quad=$ angle between the two manipulator arms, degrees

$\mathrm{O}=$ center of pulley

$\mathrm{Y}=$ perpendicular distance of the point $O$ from line $L_{1}$, in.

$P \quad=$ pivot point between $L_{1}$ and $L_{2}$

$\mathrm{X}=$ distance of the point $O$ from the point $P$ parallaled to $L_{1}$

$\mathrm{J}=$ point of cable origin

$\mathrm{K}$ = point of tangency of cable arrival at the pulley from $\mathrm{J}$

M = point of tangency of cable as it leaves pulley 


$$
\begin{array}{ll}
\mathrm{N} & =\text { point of cable termination } \\
\mathrm{A}, \mathrm{B}, \mathrm{D} & =\text { various points of reference } \\
\gamma & =\text { angle that the originating cable makes with } \mathrm{L}_{1} \text {, degrees } \\
\delta & =\text { angle that the terminating cable makes with } \mathrm{L}_{2} \text {, degrees } \\
\overline{\mathrm{JK}} & =\text { length of the originating cable, in. } \\
\overline{\mathrm{MN}} & =\text { length of the terminating cable, in. } \\
\overparen{\mathrm{KM}} & =\text { amount of wrap of the cable on the pulley, in. } \\
\phi, \psi \quad & =\text { reference angles used to obtain } \gamma, \text { degrees } \\
\epsilon, \lambda \quad & =\text { reference angles used to obtain } \delta, \text { degrees } \\
\theta \quad & =\text { angle of wrap of the cable on the pulley, degrees } \\
\sigma \quad & =\text { reference angle used to obtain } \theta, \text { degrees }
\end{array}
$$

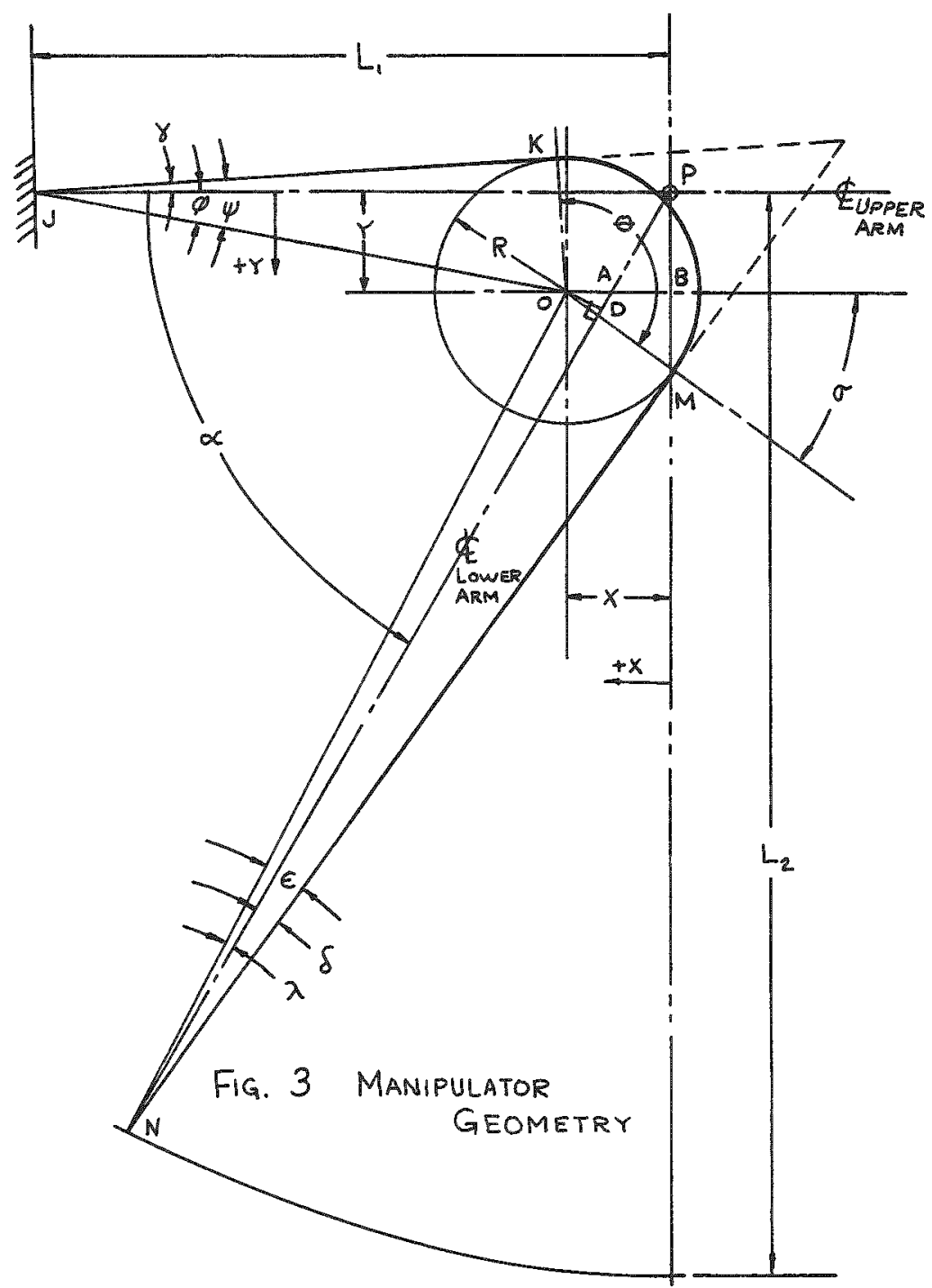


Based on Fig. 3 and its symbols, the problem can be stated as follows:

Given a manipulator with upper and lower arms $L_{1}$ and $L_{2}$ and a pulley of pitch radius $R$, it is desired to obtain a cable of constant length $C$ by moving the pulley center $O$ along some path while the angle between the arms, $a$, varies.

The problem is to obtain the proper path for constant length as a general solution. This solution is then applied to finding a practical and economical mechanism which will move the pulley center along the prescribed path.

\section{GENERAL SOLUTION}

Using Fig. 3 and its symbols, an equation for the length of the cable or tape can be obtained. In its simplest form, the length may be expressed as

$$
\mathrm{C}=\overline{\mathrm{JK}}+\overparen{\mathrm{KM}}+\overline{\mathrm{MN}} \text {. }
$$

A solution to Eq. 1 in terms of the parameters $L_{1}, L_{2}$ and $R$, the independent variable $a$, and the dependent variables $X$ and $Y$ will be obtained as follows:

$$
\begin{aligned}
& \mathrm{JK}=\sqrt{(\mathrm{JO})^{2}-\mathrm{R}^{2}} \\
& J O=\sqrt{\left(L_{1}-X\right)^{2}+Y^{2}} \\
& J P=L_{\mathbb{I}} \\
& J K=\sqrt{\left(L_{I}-X\right)^{2}+Y^{2}-R^{2}} \\
& M N=\sqrt{(N O)^{2}-R^{2}} \\
& N O=\sqrt{(A O)^{2}+(A N)^{2}-2(A O)(A N) \cos \alpha} \\
& A O=X-(A B)=X-\frac{Y}{\tan c}=X-Y \cot \alpha \\
& A P=\sqrt{(A B)^{2}+Y^{2}} \\
& A N=L_{2}-(A P)=\left[L_{2}-\sqrt{(Y \cot \alpha)^{2}+Y^{2}}\right] \\
& \text { NO }=\sqrt{(X-Y \cot \alpha)^{2}+\left[L_{2}-\sqrt{\left.(Y \cot \alpha)^{2}+Y^{2}\right]^{2}}-2(X-Y \cot \alpha)\left[L_{z}-\sqrt{(Y \cot \alpha)^{2}+Y^{2}}\right] \cos \alpha\right.} \\
& M N=\sqrt{(X-Y \cot \alpha)^{2}+\left[L_{2}-\sqrt{(Y \cot \alpha)^{2}+Y^{2}}\right]^{2}-2(X-Y \cot \alpha)\left[L_{2}-\sqrt{(Y \cot \alpha)^{2}+Y^{2}}\right] \cos \alpha-R^{2}}
\end{aligned}
$$




$$
\begin{aligned}
& \overparen{K M}=R \theta \\
& \theta=\left(90^{\circ}+\gamma+\sigma\right) \\
& \sigma=\left(90^{\circ}-a\right)+\delta \\
& \delta=\epsilon-\lambda \\
& \epsilon=\sin ^{-1}(\mathrm{R} / \mathrm{NO}) \\
& \lambda=\sin ^{-1}(\mathrm{DO} / \mathrm{NO}) \\
& \mathrm{DO}=\mathrm{AO} \sin \alpha \\
& D O=(X-Y \cot \alpha) \sin \alpha, \\
& \gamma=\gamma-\phi \\
& \%=\sin ^{-1}(\mathrm{R} / \mathrm{JO}) \\
& \phi \quad=\sin ^{-1}(\mathrm{Y} / \mathrm{JO}) \\
& \gamma=\sin ^{-1} \frac{R}{\sqrt{\left(L_{1}-X\right)^{2}+Y^{2}}}-\sin ^{-1} \frac{Y}{\sqrt{\left(L_{1}-X\right)^{2}+Y^{2}}} \\
& +\frac{\pi}{2}-\alpha+\sin ^{-1} \frac{\mathrm{R}}{\sqrt{(\mathrm{X}-\mathrm{Y} \cot \alpha)^{2}+\left[\mathrm{L}_{2}-\sqrt{(\mathrm{Y} \cot \alpha)^{2}+\mathrm{Y}^{2}}\right]^{2}-2(\mathrm{X}-\mathrm{Y} \cot \alpha)\left[\mathrm{L}_{2}-\sqrt{(\mathrm{Y} \cot \alpha)^{2}+\mathrm{Y}^{2}}\right] \cos \alpha}} \\
& \left.-\sin ^{-1} \frac{(\mathrm{X}-\mathrm{Y} \cot \alpha) \sin \alpha}{\sqrt{(\mathrm{X}-\mathrm{Y} \cot \alpha)^{2}+\left[\mathrm{L}_{2}-\sqrt{(\mathrm{Y} \cot \alpha)^{2}+\mathrm{Y}^{2}}\right]^{2}-2(\mathrm{X}-\mathrm{Y} \cot \alpha)\left[\mathrm{L}_{2}-\sqrt{(\mathrm{Y} \cot \alpha)^{2}+\mathrm{Y}^{2}}\right] \cos \alpha}}\right\}
\end{aligned}
$$

If $L_{1} / R$ or $L_{2} / R>10$, then the arc sin may be taken as equal to the angle. Then $\overparen{K M}$ can be simplified to the following:

$$
\begin{aligned}
\widehat{K M} & =R\left\{(\pi-a)+\frac{(R-Y)}{\sqrt{\left(L_{1}-X\right)^{2}+Y^{2}}}\right. \\
& \left.+\frac{R-(X-Y \cot \alpha)(\sin \alpha)}{\sqrt{(X-Y \cot \alpha)^{2}+\left[L_{2}-\sqrt{(Y \cot \alpha)^{2}+Y^{2}}\right]^{2}-2(X-Y \cot \gamma)\left[L_{2}-\sqrt{(Y \cot x)^{2}+Y^{2}}\right] \cos \alpha}}\right\}
\end{aligned}
$$

The sum of Eqs. 5, 12 and 26 yields C, Eq. 1, in terms of the variables $X, Y$ and $a$. In order to find a particular path of point $O$, a physical relationship between $X$ and $Y$ must be obtained. 
Particular Solution A (Pulley Pitch Line Tangent to Lower Arm Center Line)

To obtain this physical relationship, further information with respect to size and construction of both arms and pulley is needed. The upper arm is of tubular cast aluminum, while the lower arm consists of a cast aluminum upper section and an extruded aluminum lower section. At least seven cables are used; all of them pass through the upper arm, while five or more pass through the lower arm, the cable forming a "ribbon" through each tube. The width of the ribbon must be held to a minimum as dictated by the width of bearing needed for each of the several pulleys in the vicinity of the pivot $P$. The lower arm has four times the inertial effect of the upper arm per unit of weight; therefore, the ribbon width and the tube diameter should be held to minima in the lower arm. The ribbon must pass through the tube on a diameter to obtain the minimum size tube for a given ribbon width.

A desirable relationship between $X$ and $Y$ may be obtained if the cable leaves the pulley at the point M lying on the center line NP of the lower arm or tube (see Fig. 4). Using similar triangles, the following Eq. 27 for $X$ as function of $Y$ and $\alpha$, can be obtained:

$$
X=\frac{R}{\sin \alpha}+\frac{Y}{\tan \alpha}
$$

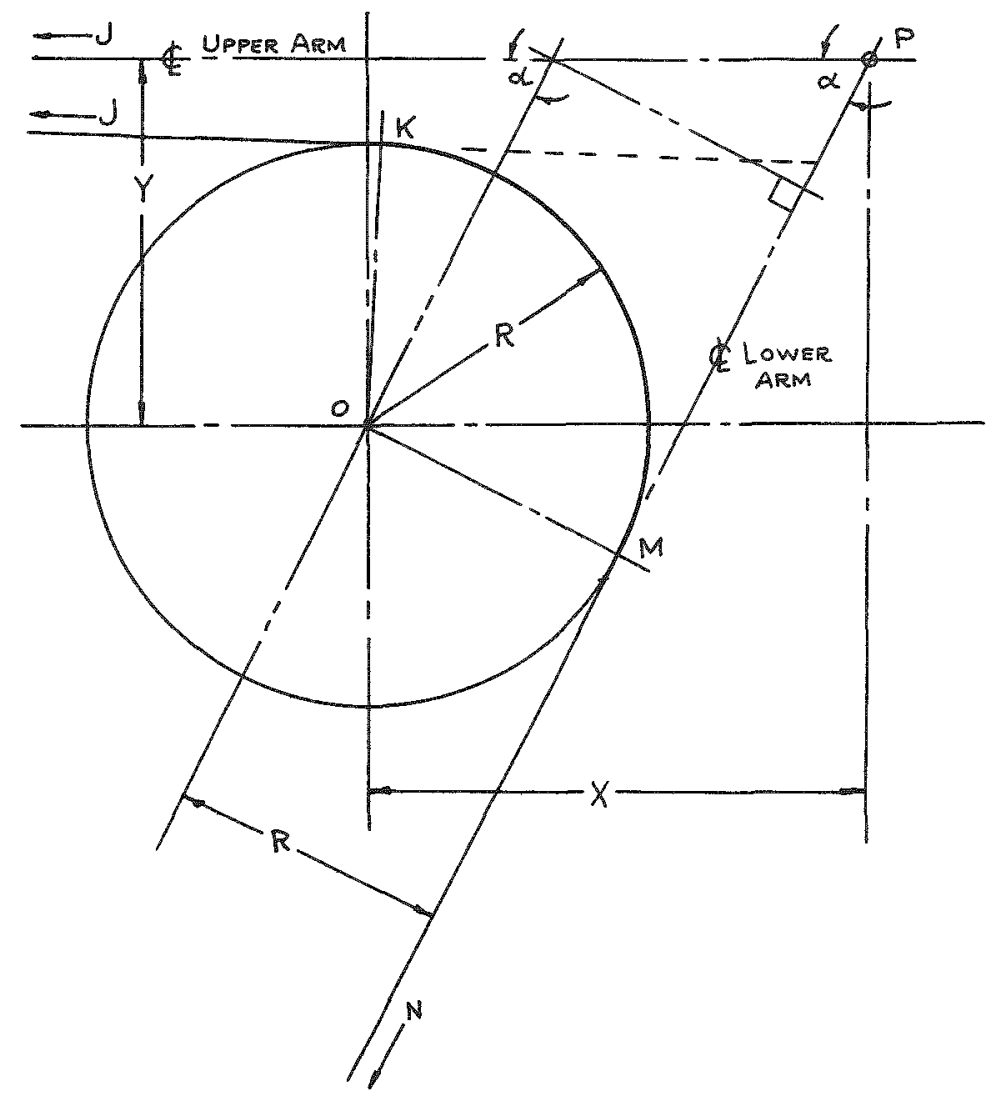

Fig. 4 Pulley Pitch line Tangent To

$$
\text { ARM CENTER LINE }
$$


Eliminating the denominators,

$$
\mathrm{X}=\mathrm{R} \csc \alpha+\mathrm{Y} \cot \alpha \quad .
$$

Substituting Eq. 28 into Eqs. 5, 12 and 26 results in the following:

$$
J K=\sqrt{\left(L_{1}-X\right)^{2}+Y^{2}-R^{2}}
$$

or

$$
J K=\sqrt{\left(L_{1}-R \csc \alpha-Y \cot \alpha\right)^{2}+Y^{2}-R^{2}}
$$

When Eq. 28 is substituted into Eq. 26, the last two terms drop out, since

$$
(\mathrm{R} \csc \alpha+\mathrm{Y} \cot \alpha-\mathrm{Y} \cot \alpha) \sin \alpha=\mathrm{R}
$$

Therefore,

$$
\widehat{K M}=R\left\{(\pi-u)+\sin ^{-1} \frac{R}{\sqrt{\left(L_{1}-X\right)^{2}+Y^{2}}}-\sin ^{-1} \frac{Y}{\sqrt{\left(L_{1}-X\right)^{2}+Y^{2}}}\right\} .
$$

If $\frac{R}{L_{1}}<0.1$, and assuming arc $\sin \gamma=\gamma$, the last two terms can be combined and simplified to yield

$$
\overparen{K M}=R\left\{(\pi-\alpha)+\frac{(R-Y)}{\sqrt{\left(L_{1}-R \csc \alpha-Y \cot \alpha\right)^{2}+Y^{2}}}\right\}
$$

$M N=\sqrt{(X-Y \cot \alpha)^{2}+\left[L_{2}-\sqrt{\left.(X+Y \cot \alpha)^{2}+Y^{2}\right]^{2}}-2(X-Y \cot \alpha)\left[L_{2}-\sqrt{(X+Y \cot \alpha)^{2}+Y^{2}}\right] \cos \alpha-R^{2}\right.}$

$M N=\sqrt{(R \csc \alpha)^{2}+\left[L_{z}-\sqrt{\left.(Y \cot \alpha)^{2}+Y^{2}\right]^{2}}-2(R \csc \alpha)\left[L_{2}-\sqrt{\left.(Y \cot \alpha)^{2}+Y^{2}\right]} \cos \alpha-R^{2}\right.\right.}$

$$
\begin{aligned}
\mathrm{MN} & =\sqrt{\mathrm{R}^{2} \csc ^{2} \alpha+\left(L_{2}-\mathrm{Y} \csc \alpha\right)^{2}-2 R \cot \alpha\left(L_{2}-Y \csc \alpha\right)-R^{2}} \\
& =\sqrt{\left(L_{1}-R \csc \alpha-Y^{\prime} \cot \alpha\right)^{2}+Y^{2}-R^{2}} \\
& +R\left\{(\pi-\alpha)+\frac{(R-Y)}{\sqrt{\left(L_{1}-R \csc \alpha-Y \cot \alpha\right)^{2}+Y^{2}}}\right\} \\
& +\sqrt{R^{2} \csc ^{2} \alpha+\left(L_{2}-Y \csc \alpha\right)^{2}-2 R \cot \alpha\left(L_{2}-Y \csc \alpha\right)-R^{2}}
\end{aligned}
$$

As a first approach to a solution, it was thought to be desirable that the difference in values for $Y$ should be kept to a minimum. In addition, $Y$ should have values such that the following is true:

$$
R-Y_{\min }=Y_{\max }-R
$$


or

$$
Y_{\max }=2 R-Y_{\min }
$$

The reason for applying the se additional conditions was again the desire to keep the size, and therefore the weight; of the upper arm to aminimum. The ideal condition is

$$
Y_{\max }=Y_{\min }=R
$$

To obtain a value for $C$ for which Eq. 39 is true, the following values for parameters were used $L_{\mathbb{I}}=30 \mathrm{in}, L_{0}=40 \mathrm{in}$, and $R=1.0 \mathrm{in}$. Using these values, a series of curves of C vs. $\alpha$ for different values of $Y$ were obtained, from which $C=69.619 \mathrm{in}$. This value for $C$ was based on 15 increments from 45 to 135 degrees. Both the range of $\alpha$ and the value of the parameters chosen are those of the Argonne National Laboratory's Electronically Controlled Master-Slave Manipulator, Model 3.

With $C=69.619$ in., a solution for $Y v s, 0$ from $E q .37$ was needed. The implicit form of this equation, which does not reduce to a simple algebraic equation, is awkward. Several values of $Y$ were obtained by laborious trial and error. The success of the trial and error solution suggested the use of a digital computer, such as the IBM 650 .

The method for programming selected was that outlined in IBM Technical Newsletter No. 11. This method is one developed by Dr.V.M. Wolontis of the Bell Telephone Laboratories: it is commonly known as the Bell $L_{I}$ system. Its actual name is a Complete Floating-Decimal Interpretive System for the IBM 650 Magnetic Drum Calculator. The actual program developed. along with an explanation of the actual notation used may be found in the Appendices.

The program used solved for values of $X$ and $Y$ at 15 -degree increments of $\alpha$ over the range from 15 to 165 degrees, a range exceeding present demands. This is a greater rarlation in a than that needed for the previously mentioned Model 3 manipulator. in Model 3, $\alpha$ varies from 45 to 135 degrees. Checking Eq. 39, using the value of $Y$ at 45 degrees for $Y_{\text {min }}$ gave a value of 1.8611 inches for $Y_{\text {max. }}$. The actual value obtained at 135 degrees was 1.8422 inches. This difference was due to an inaccuracy in the value of $C$ resulting from a graphical solution and slide rule calculation.

Further investigation, using a desk calculator for checking values of C, showed that Eq. 3915 very sensitive to small changes in C. Also, even when using a calculated value of $C$, the program falls to check the value at angles outside the 45-to 135 -degree range of the Model 3.

Future manipulators may not be limited to the range from 15 to 165 degrees. The ultumate limit might be from 0 to 360 degrees. However, a 
range of 0 to 180 degrees would allow a solution which, because of symmetry, could result in 360 degrees of movement. If w were 180 degrees, there is a unique solution to $\mathrm{C}$ :

$$
C=L_{1}+L_{2}
$$

Also, the following must be true when $\alpha=180$ degrees:

$$
\mathrm{Y}=\mathrm{R} \quad \text {. }
$$

Although Eq. 42 must be satisfied, $X$ can be any value and still satisfy the general equation for $\mathrm{C}$ at 180 degrees. However, a value of zero for $\mathrm{X}$ is unique, since it represents a point at which $O$ is nearest $P$.

Substituting C from Eq. 41 into Eq. 37, the parameters of the Model 3 were then used to determine a new path. In addition to plotting the path of point $O$ in coordinates of $X$ and $Y$, the path of $O$ was also plotted using coordinates of $\alpha$ and $L_{2}-\overline{M N}$. The curve obtained from $X-Y$ coordinates resembled a parabola. The curve of $0 \mathrm{vs} . \mathrm{L}_{2}-\overline{\mathrm{MN}}$ was nearly a straight line. Also, the parabolic curve approached a circular arc between 45 and 180 degrees.

A single problem was solved with the use of the parameters of Model 3. In addition to this solution, it was desired to know the effect of different parameters. Table I shows the range of parameters for which solutions have also been obtained.

TABLE I

Parametersfor $\mathrm{X}=\mathrm{R} \csc \%+\mathrm{Y} \cot \alpha$

\begin{tabular}{|c|c|c|c|c|}
\hline $\begin{array}{c}\text { Parameter } \\
\text { Sel }\end{array}$ & $\mathrm{L}_{1}$ & \multicolumn{1}{|c|}{$\mathrm{L}_{2}$} & \multicolumn{1}{|c|}{$\mathrm{R}$} & $\mathrm{L}_{1} / \mathrm{R}$ \\
\hline 1 & 10.0 & 10.0 & 0.5 & 20.0 \\
2 & 10.0 & 10.0 & 0.75 & 13.3 \\
3 & 10.0 & 10.0 & 1.0 & 10.0 \\
4 & 20.0 & 20.0 & 0.5 & 40.0 \\
5 & 20.0 & 20.0 & 0.75 & 26.6 \\
6 & 20.0 & 20.0 & 2.00 & 10.0 \\
7 & 10.0 & 40.0 & 1.0 & 10.0 \\
8 & 30.0 & 40.0 & 1.0 & 30.0 \\
9 & 40.0 & 40.0 & 2.00 & 20.0 \\
10 & 36.0 & 48.0 & 2.0 & 18.0 \\
\hline
\end{tabular}

The tabular and graphical solutions to these different parameter sets follow. In addition, the solutions to parameter set 12 are given as a special problem having $C=69.619 \mathrm{in}$. 
TABLE II

Parameter Set $1 L_{1}=100, L_{2}=100$, $R=05$ and $L_{1} / R=200$

\begin{tabular}{|c|c|c|c|c|}
\hline c & $\mathrm{Y}$ & $\mathrm{X}$ & $M N$ & $L_{2}-M N$ \\
\hline 15 & -0.306 & 0790 & 9316 & 0684 \\
\hline 30 & -0143 & 0752 & 9421 & 0579 \\
\hline 45 & -0007 & 0700 & 9509 & 0491 \\
\hline 60 & 0109 & 0640 & 9586 & 0414 \\
\hline 75 & 0206 & 0573 & 9653 & 0347 \\
\hline 90 & 0.287 & 0.500 & 9713 & 0287 \\
\hline 105 & 0.353 & 0.423 & 9.768 & 0232 \\
\hline 120 & 0.406 & 0343 & 9820 & 0180 \\
\hline 135 & 0446 & 0261 & 9.868 & 0132 \\
\hline 150 & $*$ & $*$ & $*$ & $*$ \\
\hline 165 & * & * & $*$ & $*$ \\
\hline 180 & 0500 & 0000 & 10000 & 0.000 \\
\hline
\end{tabular}

TABLE III

Parameter Set $2 \mathrm{~L}_{1} 100, \mathrm{~L}_{2}=100$, $R=0.75$ and $L_{1} / R=133$

\begin{tabular}{|c|c|c|c|c|}
\hline & $\mathrm{Y}$ & $\mathrm{X}$ & $\mathrm{MN}$ & $\mathrm{L}_{2}-\mathrm{MN}$ \\
\hline $15 * *$ & -0455 & 1200 & 8959 & 1041 \\
\hline $30 * *$ & -0210 & 1130 & 9121 & 0879 \\
\hline 45 & -0005 & 1056 & 9257 & 0743 \\
\hline 60 & 0167 & 0903 & 9373 & 0627 \\
\hline 75 & 0312 & 0800 & 9470 & 0524 \\
\hline 90 & $0 \pm 33$ & 0750 & 9507 & $0 \pm 33$ \\
\hline 105 & 0532 & 0634 & 9650 & 0350 \\
\hline 120 & 0610 & 0514 & 9728 & 0272 \\
\hline 135 & 0071 & 0390 & 9802 & 0198 \\
\hline 150 & 0712 & 0200 & 9875 & 0125 \\
\hline 165 & 0735 & 0150 & 9900 & 0040 \\
\hline 180 & 0750 & 0000 & 10000 & 0000 \\
\hline
\end{tabular}

* Data missing

* Data do not satistr assumptions because of small angle approsimation for $r$

\section{TABLE IV}

Parameter Set $3 L_{1}=100, L_{2}=100$, $R=10$ and $L_{1} / R=100$

\begin{tabular}{|c|c|c|c|c|}
\hline$\omega$ & $Y$ & $x$ & $M N$ & $\mathrm{~L}_{2}-\mathrm{MN}$ \\
\hline 15 & -0601 & 1622 & 8589 & 1411 \\
\hline 30 & -0273 & 1527 & 8814 & 1186 \\
\hline 45 & 0000 & 1414 & 9005 & 0995 \\
\hline 60 & 0228 & 1287 & 9159 & 0841 \\
\hline 75 & 0420 & 1148 & 9297 & 0703 \\
\hline 90 & 0580 & 1.000 & 9420 & 0580 \\
\hline 105 & 0710 & 0.845 & 9532 & 0468 \\
\hline 120 & 0815 & 0684 & 9636 & 0364 \\
\hline 135 & 0895 & 0519 & 9734 & 0266 \\
\hline 150 & 0951 & 0353 & 9.830 & 0170 \\
\hline 165 & 0.981 & 0202 & 9.941 & 0.059 \\
\hline 180 & 1000 & 0000 & 10000 & 0.000 \\
\hline
\end{tabular}

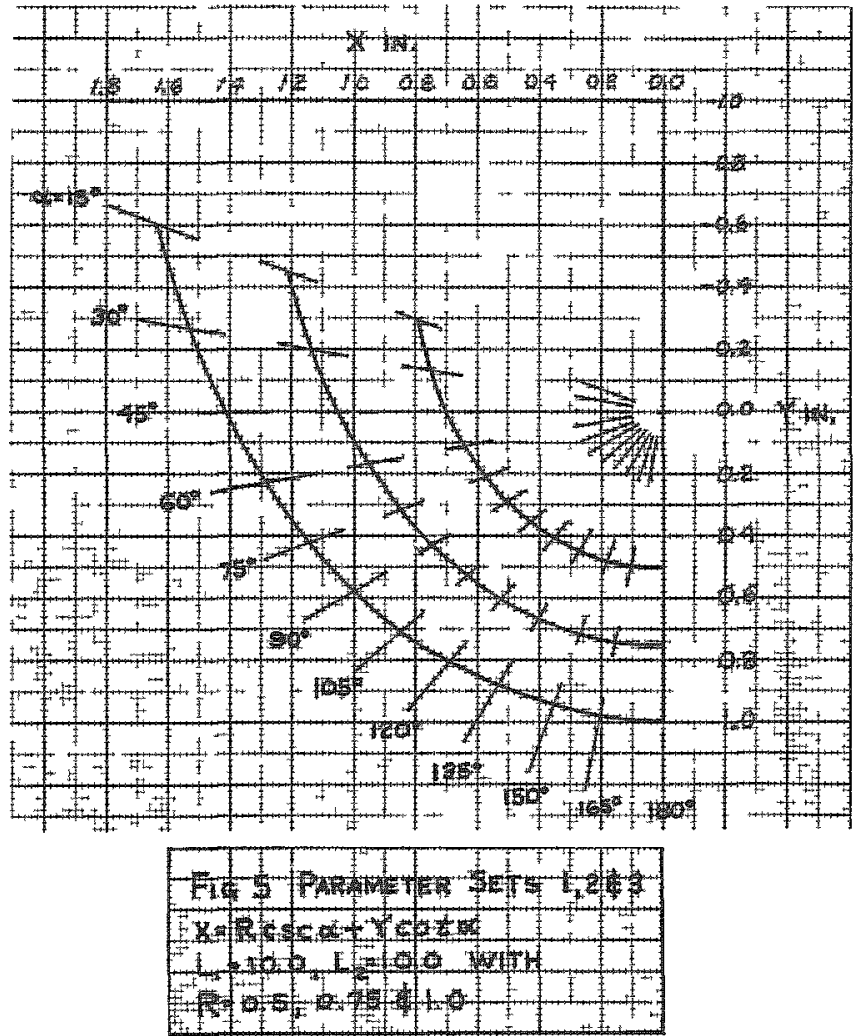


TABLEV

Parameter Set $4 L_{1}=200, L_{2}=200$, $R=0.5$ and $L_{1} / R=40$

\begin{tabular}{|c|c|c|c|c|}
\hline & $Y$ & $x$ & $M N$ & $L_{2}-M N$ \\
\hline 15 & -0.308 & 0782 & 19324 & 0.676 \\
\hline 30 & -0.147 & 0746 & 19427 & 0573 \\
\hline 45 & -0.010 & 0697 & 19.514 & 0486 \\
\hline 60 & 0106 & 0639 & 19588 & 0412 \\
\hline 75 & 0204 & 0572 & 19.655 & 0345 \\
\hline 90 & 0286 & 0500 & 19714 & 0286 \\
\hline 105 & 0.352 & 0423 & 19769 & 0231 \\
\hline 120 & 0406 & 0343 & 19820 & 0180 \\
\hline 135 & 0.446 & 0261 & 19869 & 0131 \\
\hline 150 & 0473 & 0.180 & 19919 & 0081 \\
\hline 165 & 0487 & 0115 & 19985 & 0015 \\
\hline 180 & 0.500 & 0000 & 20.000 & 0.000 \\
\hline
\end{tabular}

TABLE VII

Parameter Set 6: $L_{l}=20.0, L_{2}=20.0$, $R=2.00$ and $L_{1} / R=10.0$

\begin{tabular}{|c|c|c|c|c|}
\hline$a$ & $Y$ & $X$ & $M N$ & $L_{2}-M N$ \\
\hline $15 *$ & -1.202 & 3.243 & 17.178 & 2.822 \\
$30 *$ & -0.546 & 3.054 & 17628 & 2.372 \\
$45 *$ & 0.000 & 2.828 & 18.000 & 2.000 \\
60 & 0.457 & 2.573 & 18317 & 1.683 \\
75 & 0.841 & 2.296 & 18594 & 1406 \\
90 & 1.160 & 2.000 & 18.840 & 1.160 \\
105 & 1.422 & 1.690 & 19.064 & 0.936 \\
120 & 1632 & 1.367 & 19.270 & 0.730 \\
135 & 1.792 & 1.036 & 19.465 & 0.535 \\
150 & 1.905 & 0700 & 19.654 & 0.346 \\
165 & 1.974 & 0.360 & 19.837 & 0.163 \\
180 & 2000 & 0.000 & 20.000 & 0.000 \\
\hline
\end{tabular}

* Data do not satisfy assumptions because of small angle approximation for $\gamma$.
TABLE VI

Parameter Set $5 L_{1}=200, L_{2}=200$, $R=075$ and $L_{1} / R=260$

\begin{tabular}{|r|c|c|c|c|c|}
\hline & \multicolumn{1}{|c|}{$\mathrm{Y}^{\prime}$} & $\mathrm{X}$ & $\mathrm{MN}$ & $\mathrm{L}_{2}-\mathrm{MN}$ \\
\hline 15 & -0441 & 1 & 179 & 18981 & 1019 \\
30 & -0217 & 1.124 & 19136 & 0864 \\
45 & -0012 & 1049 & 19267 & 0.733 \\
60 & 0.162 & 0.959 & 19380 & 0620 \\
75 & 0308 & 0859 & 19480 & 0520 \\
90 & 0430 & 0 & 750 & 19570 & 0.430 \\
105 & 0.530 & 0.635 & 19653 & 0347 \\
120 & 0.610 & 0514 & 19729 & 0271 \\
135 & 0.070 & 0 & 391 & 19802 & 0.198 \\
150 & 0.712 & 0267 & 19875 & 0125 \\
165 & 0.734 & 0 & 159 & 19.964 & 0.036 \\
180 & 0.750 & 0.000 & 20000 & 0.000 \\
\hline
\end{tabular}
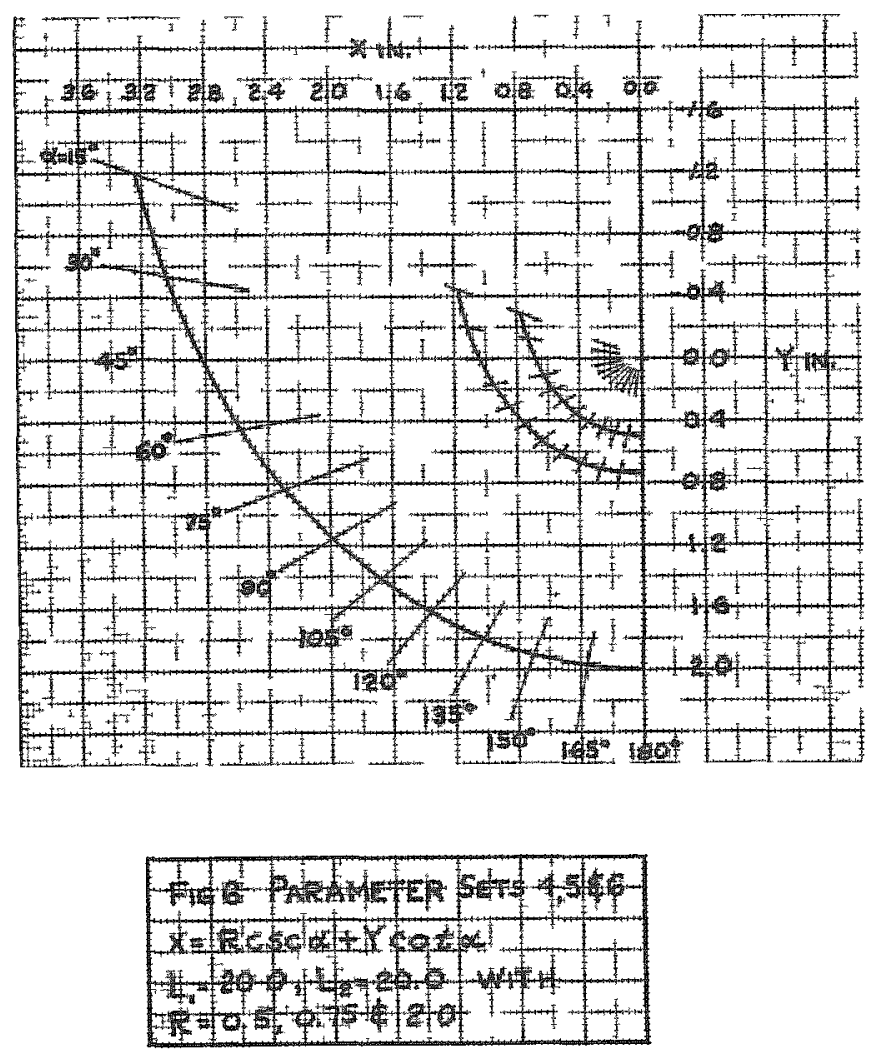
TABLE VIII

Parameter Set 7: $L_{1}=10.0, L_{2}=40.0$, $R=1.0$ and $L_{1} / R=10.0$

\begin{tabular}{|c|c|c|c|c|}
\hline$\alpha$ & $\mathrm{Y}$ & $\mathrm{X}$ & $\mathrm{MN}$ & $\mathrm{L}_{2}-\mathrm{MN}$ \\
\hline 15 & -0.601 & 1.622 & 38.589 & 1.411 \\
30 & -0.273 & 1.527 & 38.814 & 1.186 \\
45 & 0.000 & 1.414 & 39.000 & 1.000 \\
60 & 0.228 & 1.287 & 39.159 & 0.841 \\
75 & 0.419 & 1.148 & 39.297 & 0.702 \\
90 & 0.580 & 1.000 & 39.420 & 0.580 \\
105 & $*$ & $*$ & $*$ & $*$ \\
120 & $*$ & $*$ & $*$ & $*$ \\
135 & $*$ & $*$ & $*$ & $*$ \\
150 & $*$ & $*$ & $*$ & $*$ \\
165 & $*$ & $*$ & $*$ & $*$ \\
180 & $*$ & $*$ & $*$ & $*$ \\
\hline
\end{tabular}

* Data missing

TABLE X

Parameter Set 9: $L_{1}=40.0, L_{2}=40.0$, $R=2.0$ and $L_{1} / R=20.0$

\begin{tabular}{|r|c|c|c|c|}
\hline$\alpha$ & $\mathrm{Y}$ & $\mathrm{X}$ & $\mathrm{MN}$ & $\mathrm{L}_{2}-\mathrm{MN}$ \\
\hline 15 & -1.223 & 3.162 & 37.262 & 2.738 \\
30 & -0.573 & 3.007 & 37.682 & 2.318 \\
45 & -0.026 & 2.803 & 38.036 & 1.964 \\
60 & 0.437 & 2.562 & 38.341 & 1.659 \\
75 & 0.826 & 2.292 & 38.609 & 1.391 \\
90 & 1.150 & 2.000 & 38.850 & 1.150 \\
105 & 1.417 & 1.691 & 39.069 & 0.931 \\
120 & 1.629 & 1.369 & 39.273 & 0.727 \\
135 & 1.793 & 1.035 & 39.464 & 0.536 \\
150 & 1.905 & 0.700 & 39.654 & 0.346 \\
165 & 1.970 & 0.376 & 39.854 & 0.146 \\
180 & 2.000 & 0.000 & 40.000 & 0.000 \\
\hline
\end{tabular}

TABLE IX

Parameter Set 8: $L_{1}=30.0, L_{2}=40.0$, $\mathrm{R}=1.0$ and $\mathrm{L}_{1} / \mathrm{R}=30.0$

\begin{tabular}{|r|c|c|c|c|}
\hline$a$ & $\mathrm{Y}$ & $\mathrm{X}$ & $\mathrm{MN}$ & $\mathrm{L}_{2}-\mathrm{MN}$ \\
\hline 15 & -0.615 & 1.569 & 38.643 & 1.357 \\
30 & -0.291 & 1.496 & 38.850 & 1.150 \\
45 & -0.017 & 1.397 & 39.024 & 0.976 \\
60 & 0.215 & 1.279 & 39.175 & 0.825 \\
75 & 0.410 & 1.145 & 39.307 & 0.693 \\
90 & 0.573 & 1.000 & 39.426 & 0.574 \\
105 & 0.707 & 0.846 & 39.536 & 0.464 \\
120 & 0.813 & 0.685 & 39.638 & 0.362 \\
135 & 0.894 & 0.520 & 39.735 & 0.265 \\
150 & 0.951 & 0.354 & 39.830 & 0.170 \\
165 & 0.981 & 0.202 & 39.941 & 0.059 \\
180 & 1.000 & 0.000 & 40.000 & 0.000 \\
\hline
\end{tabular}

TABLEXI

Parameter Set 10: $\mathrm{L}_{1}=36.0, \mathrm{~L}_{2}=48.0$, $R=2.00$ and $L_{1} / R=18.0$

\begin{tabular}{|c|c|c|c|c|}
\hline$\alpha$ & $\mathrm{Y}$ & $\mathrm{X}$ & $\mathrm{MN}$ & $\mathrm{L}_{2}-\mathrm{MN}$ \\
\hline 15 & -1.221 & 3.171 & 45.253 & 2.747 \\
30 & -0.570 & 3.012 & 45.677 & 1.968 \\
45 & -0.023 & 2.805 & 46.032 & 1.968 \\
60 & 0.439 & 2.563 & 46.339 & 1.661 \\
75 & 0.827 & 2.292 & 46.607 & 1.393 \\
90 & 1.151 & 2.000 & 46.849 & 1.151 \\
105 & 1.417 & 1.691 & 47.069 & 0.931 \\
120 & 1.629 & 1.369 & 47.273 & 0.727 \\
135 & 1.791 & 1.037 & 47.467 & 0.533 \\
150 & 1.905 & 0.700 & 47.654 & 0.346 \\
165 & $*$ & $*$ & $*$ & $*$ \\
180 & 2.000 & 0.000 & 48.000 & 0.000 \\
\hline
\end{tabular}

* Data missing 

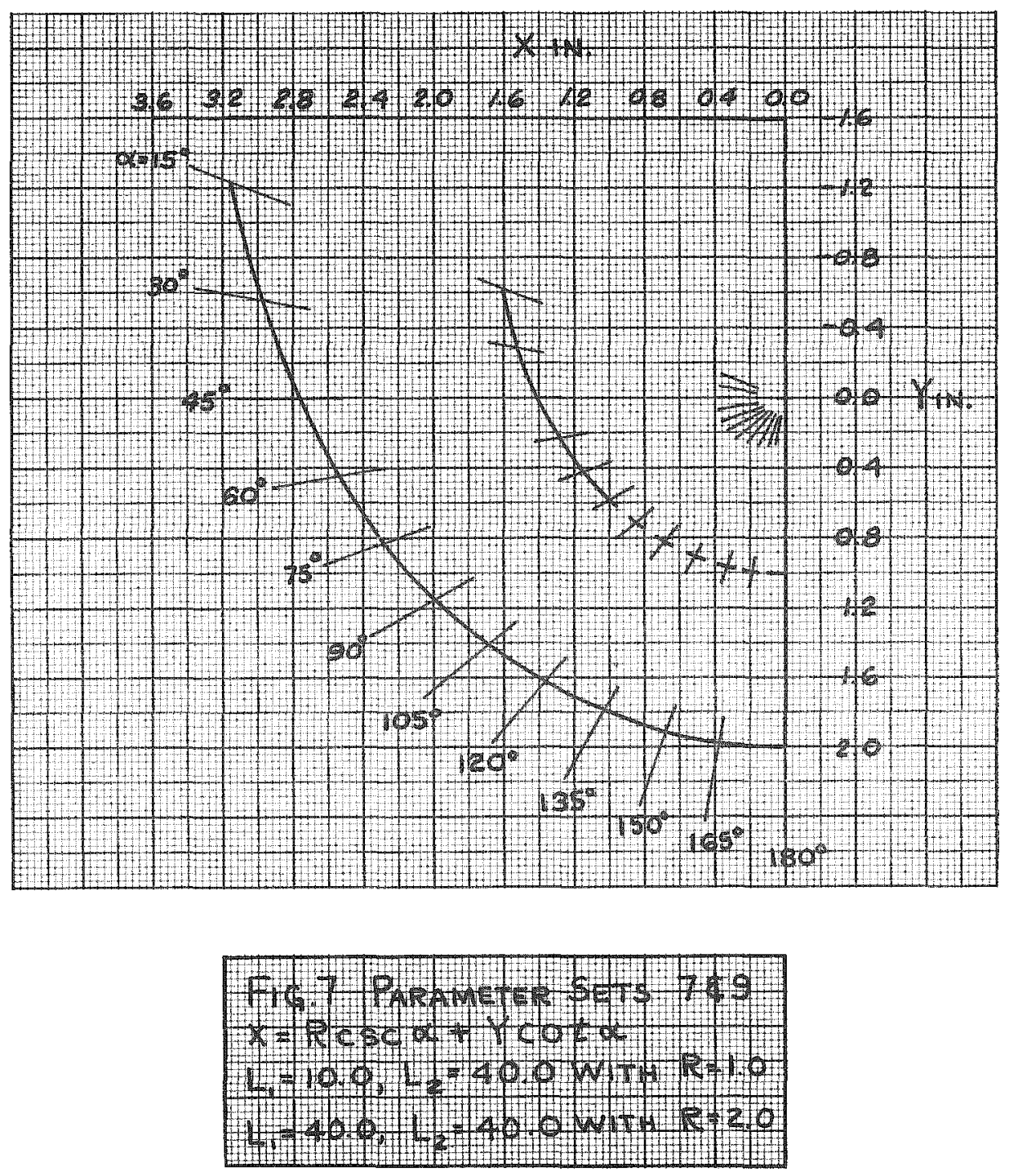
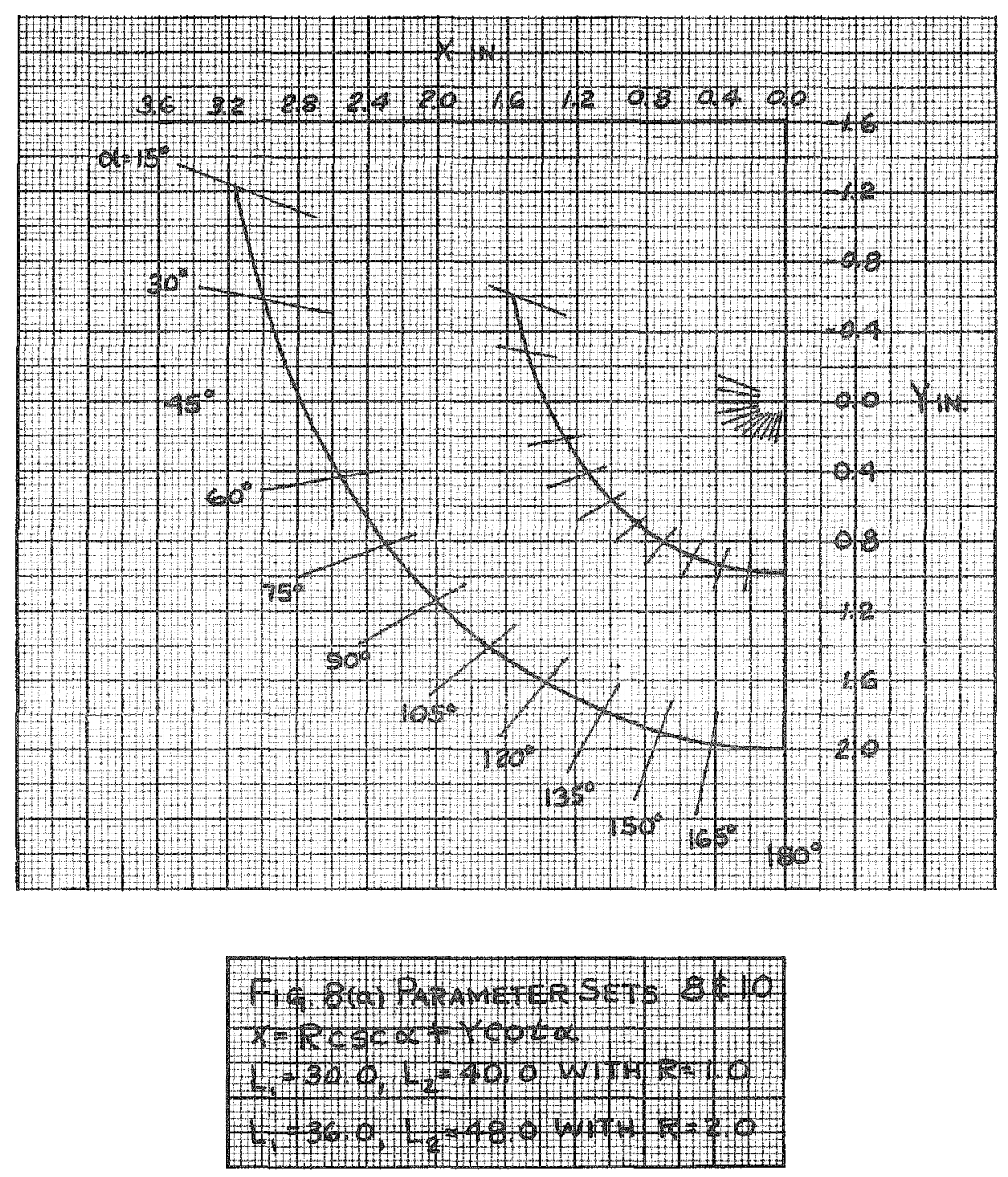
TABLE XII

Parameter Set $11 L_{1}=30.0, L_{2}=40.0$, $R=10$ and $L_{1} / R=300$

$$
\begin{gathered}
\text { SPECIAL PROBLEM } \\
\mathrm{X}=\mathrm{R} \operatorname{cSC}+\mathrm{Y} \cot \\
\text { Aiso } \\
\mathrm{JK}+\overparen{\mathrm{KM}}+\mathrm{MN}=69619
\end{gathered}
$$

\begin{tabular}{|c|c|c|c|c|}
\hline & $\mathrm{Y}$ & $\mathrm{X}$ & $\mathrm{MN}$ & $\mathrm{L}_{2}-\mathrm{MN}$ \\
\hline $15 * *$ & -0.563 & 1.764 & 38.412 & 1.558 \\
$30 * *$ & -0.188 & 1.675 & 38643 & 1357 \\
45 & 0.139 & 1553 & 38.804 & 1196 \\
60 & 0.434 & 1.405 & 38921 & 1079 \\
75 & 0.701 & 1.223 & 39.006 & 0.994 \\
90 & 0.952 & 1.000 & 39048 & 0.952 \\
105 & 1.203 & 0.713 & 39.022 & 0.978 \\
120 & 1.479 & 0.301 & 38.869 & 1.131 \\
135 & 1.842 & -0.428 & 38395 & 1.605 \\
$150 * *$ & 2.503 & -2.336 & 36.725 & 3.275 \\
$165 * *$ & $*$ & $*$ & $*$ & $*$ \\
$180 * *$ & $*$ & $*$ & $*$ & $*$ \\
\hline
\end{tabular}

* Data missing

* Data do not satisty assumptions because of small angle appros1mation for $\gamma$ or $C \neq 69.619$
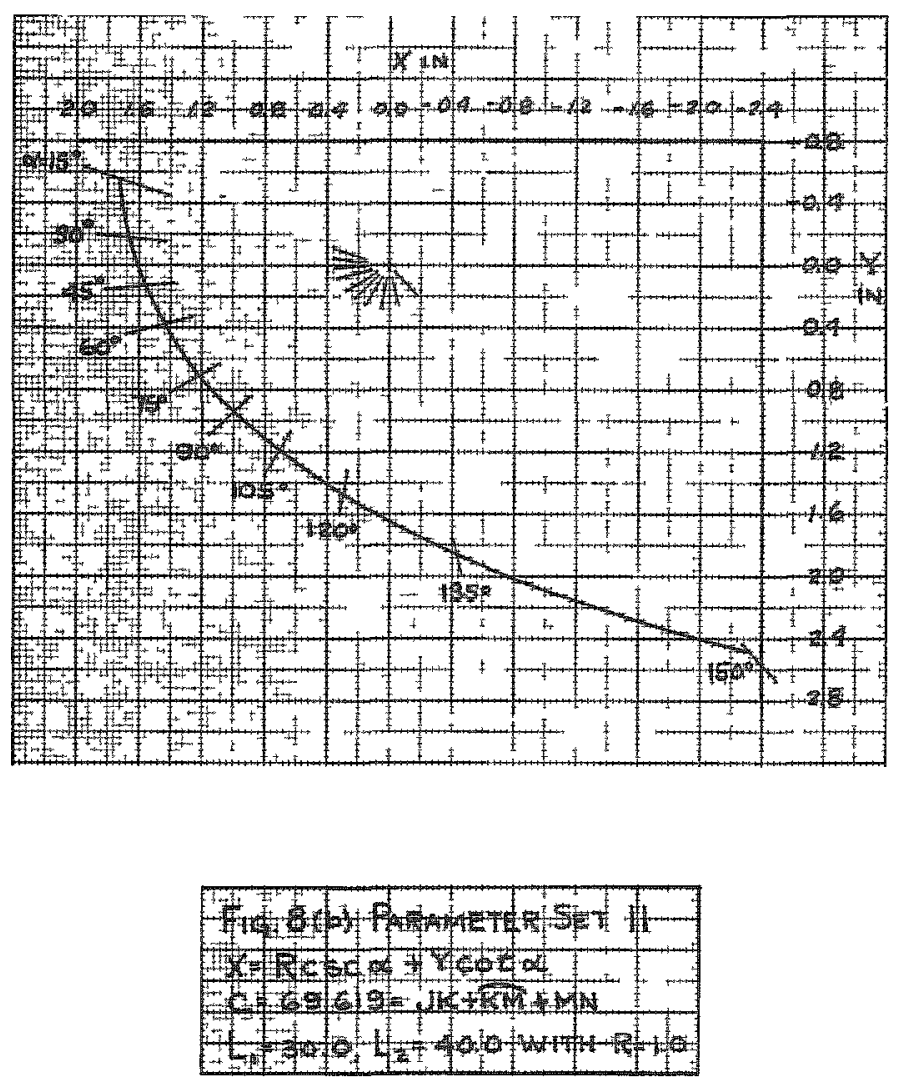


\section{Summary}

A review of the results can best be had from the graphical presentations in Figs. 5 through 8 . The magnitudes of $X$ and $Y$ vary almost exclusively as a function of $R$. The tabular data, however, do indicate that the length of $L_{1}$ does influence the result; $L_{2}$ does not affect the result since the point $M$ remains on the Line NP. It will be noticed that the path, although parabolic in shape, does approach the arc of a circle for a large portion of the curve.

Mechanisms to cause the pulley center to follow the analytically determined paths more or less accurately were next investigated.

Mechanism 1 used a cam, the precedent being Model 3, with the future possible requirement of a large $\alpha$ and the maintenance of cam weight. The cam proposal appears impractical. In addition, accurate cams are very expensive.

Mechanism 2 considered the use of a gear and rack to drive a slider on the lower arm. This mechanism is feasible since the movement of the pulley center with respect to the lower arm is nearly linear. As in the case of the cam, weight and cost are high.

Other mechanisms, such as a four-bar linkage or a slidecrank, were impracticable for one reason or another.

Particular Solution B (Pulley Center Moving on the Arc of a Circle)

As a possible method for reducing complexity, other physical relations between $X$ and $Y$ were investigated. For angles of $\alpha$ greater than 45 degrees, the parabolic curves obtained as previously mentioned appear as an arc of a circle. Using graphical means, the center of the circle arc for each of the Parameter Sets of Table I was found. Using these centers an approximate general solution was obtained when the center of the circular arc lay at the coordinates, $x=0$, and $y=-0.5 R$, the radius of the circular arc being $1.5 R$. This rel ation is accurate at $\alpha=180$ degrees. For other angles the relation is a very close approximation to the solutions obtained. Figure 9 summarizes the new relation between $X$ and $Y$.

This relationship allows a simpler solution to the four-bar linkage, since the point $O$ lies on the follower rather than on the coupler. The length of the fixed link is $0.5 \mathrm{R}$ for all parameters. This allows easier graphical solution for the remaining links. 


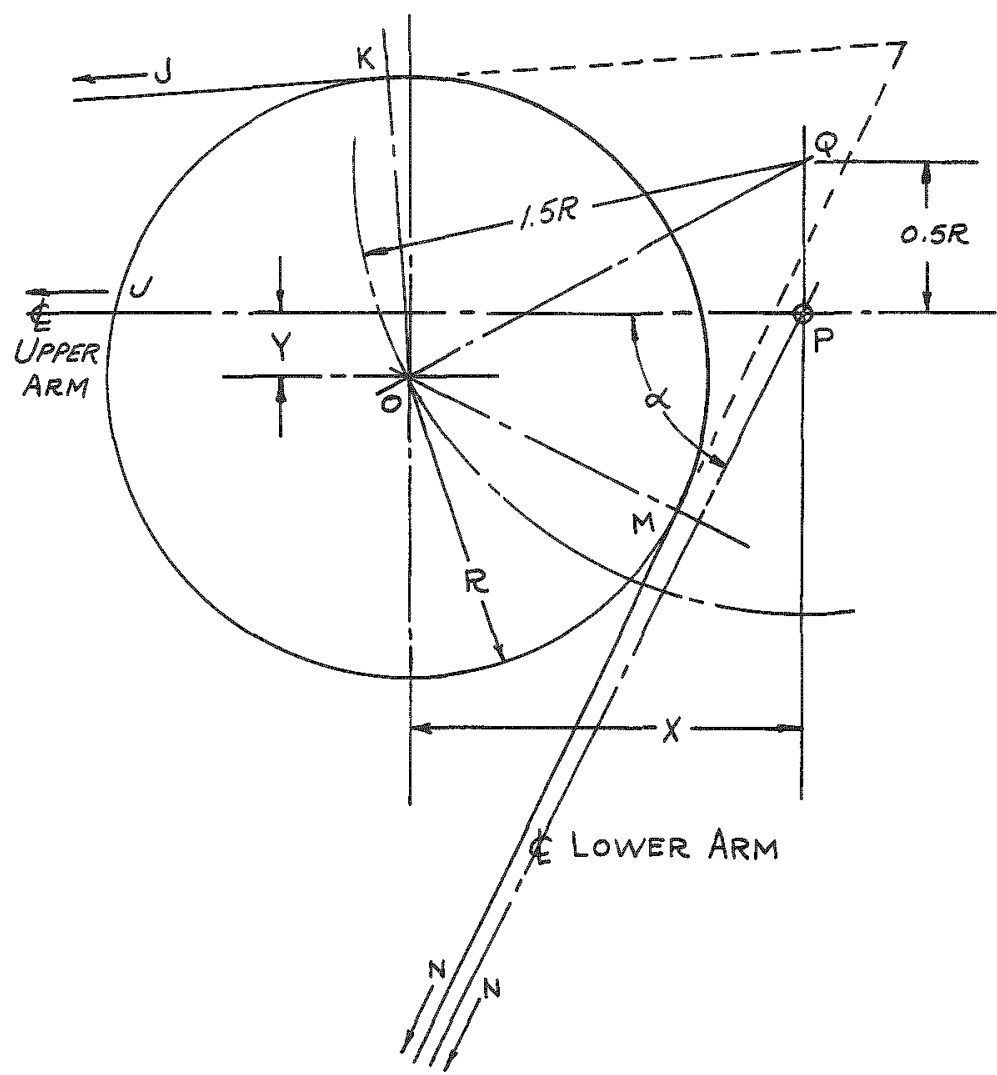

Fig 9 Pulley Center Moving

ON THE

ARC OF A CIRCLE

A second simplification may be the use of a cam whose working profile is a straight line cam. A third solution involving a single link is applicable to cases in which a line parallel to the link bisects the included angle between the lines $\mathrm{JK}$ and $\mathrm{MN}$.

The geometry shown in Fig. 9 gives the following equations needed for computing $X$ and $Y$. Since $Q$, the center of the circular arc, has the coordinates $x=0$ and $y=0.5 R$, and the radius of the circle is equal to $1.5 R$, an equation for this particular circle can be written as

$$
X^{2}+(Y+0.5 R)^{2}=2.25 R^{2}
$$

From this,

$$
X=\sqrt{2.25 R^{2}-(Y+0.5 R)^{2}} .
$$

Substituting this equation for $X$ into Equations 5,12 and 26 ,

$$
J K=\sqrt{\left[L_{1}-\sqrt{2.25 R^{2}-(Y+0.5 R)^{2}}\right]^{2}+Y^{2}-R^{2}}
$$




$$
\begin{aligned}
& \widehat{K M}=R\left\{(\pi-\alpha)+\frac{(R-Y)}{\sqrt{\left[L_{1}-\sqrt{2.25 R^{2}-(Y+0.5 R)^{2}}\right]^{2}+Y^{2}}}\right. \\
& R-(\sin \alpha) \sqrt{2.25 R^{2}-(Y+0.5 R)^{2}}+Y \cos \lambda \\
& +\frac{R-(\sin \alpha) \sqrt{2.25 R^{2}-(Y+0.5 R)^{2}+Y \cos \alpha}}{\sqrt{\left[\sqrt{2.25 R^{2}-(Y+0.5 R)^{2}}-Y \cot \alpha\right]^{2}+\left[L_{2}-\sqrt{(Y \cot \alpha)^{2}+Y^{2}}\right]^{2}-2 \cos \alpha\left[\sqrt{2.25 R^{2}-(Y+0.5 R)^{2}}-Y \cot \alpha\right]\left[I_{g}-\sqrt{(Y \cot \alpha)^{2}+Y^{2}}\right]}} \\
& M N=\sqrt{\left[\sqrt{2.25 R^{2}-(Y+0.5 R)^{2}}-Y \cot \alpha\right]^{2}+\left[L_{2}-\sqrt{(Y \cot \alpha)^{2}+Y^{2}}\right]^{2}-2 \cos \alpha\left[\sqrt{2.25 R^{2}-(Y+0.5 R)^{2}}-Y \cot \alpha\right]\left[L_{2}-\sqrt{(Y \cot \alpha)^{2}+Y^{2}}\right]-R^{2}} \\
& C=L_{1}+L_{2}=\sqrt{\left[L_{1}-\sqrt{2.25 R^{2}-(Y+0.5 R)^{2}}\right]^{2}+Y^{2}-R^{2}} \\
& +R\left\{(\pi-\alpha)+\frac{(R-Y)}{\sqrt{\left[L_{1}-\sqrt{2.25 R^{2}-(Y+0.5 R)^{2}}\right]^{2}+Y^{2}}}\right. \\
& \left.+\frac{\left[R-(\sin \alpha) \sqrt{2.25 R^{2}-(Y+0.5 R)^{2}}+Y \cos \alpha\right]}{\sqrt{\left[\sqrt{2.25 R^{2}-(Y+0.5 R)^{2}}-Y \cot \alpha\right]^{2}+\left[I_{2}-\sqrt{(Y \cot \alpha)^{2}+Y^{2}}\right]^{2}-2 \cos \alpha\left[\sqrt{2.25 R^{2}-(Y+0.5 R)^{2}}-Y \cot \alpha\right]\left[I_{2}-\sqrt{(Y \cot \alpha)^{2}+Y^{2}}\right]}}\right\} \\
& +\sqrt{\left[\sqrt{2.25 R^{2}-(Y+0.5 R)^{2}}-Y \cot \alpha\right]^{2}+\left[L_{2}-\sqrt{(Y \cot \alpha)^{2}+Y^{2}}\right]^{2}-2 \cos \left[\sqrt{2.25 R^{2}-(Y+0.5 R)^{2}}-Y \cot \alpha\right]\left[L_{2}-\sqrt{(Y \cot \alpha)^{2}+Y^{2}}\right]-R^{2}}
\end{aligned}
$$

Using Eq. 48, a new IBM program, similar to the one used for Eq. 37, was developed. This program can be found in the appendices.

Table XIII shows the variation of parameters for which solutions to Eq. 48 have been obtained. The program was arranged to produce $\gamma$ and $\delta$ (Fig. 3) during the course of the computation for $Y$.

TABIE XIII

Parameters for $X=\sqrt{2.25 R^{2}-(Y+0.5 R)^{2}}$

\begin{tabular}{|c|c|c|c|c|c|}
\hline $\begin{array}{c}\text { Parameter } \\
\text { Set }\end{array}$ & $\mathrm{L}_{1}$ & $\mathrm{~L}_{2}$ & $\mathrm{R}$ & $\mathrm{L}_{1} / \mathrm{R}$ & $\mathrm{L}_{2} / \mathrm{R}$ \\
\hline 12 & 10.0 & 10.0 & 0.5 & 20.0 & 20.0 \\
13 & 10.0 & 10.0 & 0.75 & 13.3 & 13.3 \\
14 & 10.0 & 10.0 & 1.0 & 10.0 & 10.0 \\
15 & 20.0 & 20.0 & 0.5 & 40.0 & 40.0 \\
16 & 20.0 & 20.0 & 1.0 & 20.0 & 20.0 \\
17 & 20.0 & 20.0 & 2.0 & 10.0 & 10.0 \\
18 & 10.0 & 40.0 & 0.5 & 20.0 & 80.0 \\
19 & 10.0 & 40.0 & 1.0 & 10.0 & 40.0 \\
20 & 40.0 & 40.0 & 2.0 & 20.0 & 20.0 \\
21 & 10.0 & 20.0 & 0.5 & 20.0 & 40.0 \\
22 & 10.0 & 20.0 & 1.0 & 10.0 & 20.0 \\
23 & 30.0 & 30.0 & 1.0 & 30.0 & 30.0 \\
24 & 30.0 & 40.0 & 1.0 & 30.0 & 40.0 \\
\hline
\end{tabular}


These angles become important when a possible solution utilizing a single link is to be investigated. Figure 10 shows the relationship of a single link. Several symbols, not shown on Fig. 3, are necessary for further clarification:

$\beta=$ the included angle between the lines JK and $M N$ extended, degrees $\mu=$ the angle between the lines $O Q$ and $J P$, degrees

$\rho=$ the angle between the bisector of $\beta$ and the line JP, degrees

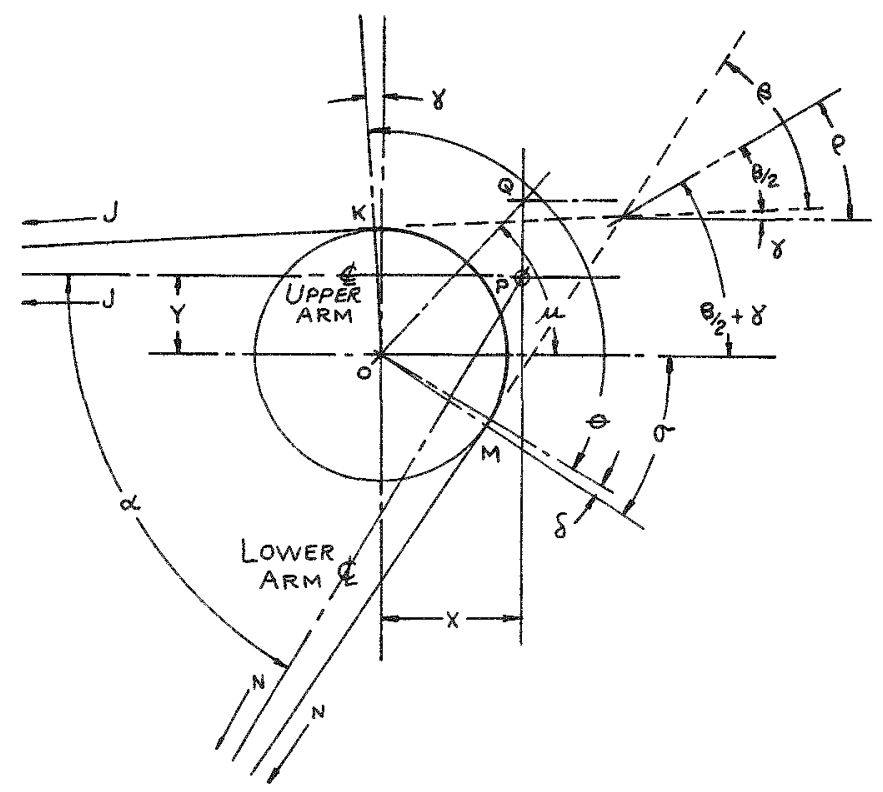

Fig. 10 Single Link Relationships

In order to have an exact solution with a single link, certain conditions among these angles must be satisfied. In addition to $C$ being constant, $\rho$ must be equal to $\mu$. The following equations simplify the angles $\rho$ and $\mu$ into terms which may be obtained during computations for $X$ and $Y$ :

$$
\rho=\frac{1}{2} \beta+\gamma
$$

$$
\frac{1}{2} \beta=90^{\circ}-\frac{1}{2} \theta \text {. }
$$

Using Equations 14 and 15 ,

$$
\begin{aligned}
& \theta=\left(180^{\circ}-\alpha\right)+\gamma+\delta \\
& \frac{1}{2} \theta=90^{\circ}-\frac{1}{2}(\alpha-\gamma-\delta) \\
& \frac{1}{2} \beta=\frac{1}{2}(\alpha-\gamma-\delta) \\
& \rho=\frac{1}{2}(\alpha-\gamma-\delta)+\gamma \\
& \rho=\frac{1}{2}(\alpha+\gamma-\delta) \\
& \mu=\tan ^{-1}\left(\frac{Y+0.5 R}{X}\right)=\sin ^{-1}\left(\frac{Y+0.5 R}{1.5 R}\right)
\end{aligned}
$$


TABLE XIV

Parameter Set 12 :

$L_{1}=10.0, L_{2}=10.0, R=0.50$, $L_{1} / R=20.0$, and $L_{2} / R=20.0$

\begin{tabular}{|r|c|c|c|c|}
\hline$a$ & $\mathrm{Y}$ & $\mathrm{X}$ & $\rho$ & $\mu$ \\
\hline 45 & $*$ & $*$ & $*$ & $*$ \\
60 & 0 & 0.707 & $31^{\circ} 53^{\prime}$ & $19^{\circ} 30^{\prime}$ \\
75 & 0.081 & 0.673 & $39^{\circ} 10^{\prime}$ & $26^{\circ} 15^{\prime}$ \\
90 & 0.169 & 0.622 & $46^{\circ} 22^{\prime}$ & $33^{\circ} 57^{\prime}$ \\
105 & 0.255 & 0.555 & $53^{\circ} 32^{\prime}$ & $42^{\circ} 20^{\prime}$ \\
120 & 0.333 & 0.471 & $60^{\circ} 43^{\prime}$ & $51^{\circ} 5^{\prime}$ \\
135 & 0.400 & 0.375 & $67^{\circ} 56^{\prime}$ & $59^{\circ} 59^{\prime}$ \\
150 & 0.449 & 0.271 & $75^{\circ} 23^{\prime}$ & $68^{\circ} 49^{\prime}$ \\
165 & 0.479 & 0.177 & $82^{\circ} 36^{\prime}$ & $76^{\circ} 20^{\prime}$ \\
180 & 0.500 & 0.000 & $90^{\circ} 0$ & $90^{\circ} 0^{\prime}$ \\
\hline
\end{tabular}

* Data missing

\section{TABLE XVI}

Parameter Set 14:

$L_{1}=10.0, L_{2}=10.0, R=1.0$, $L_{1} / R=10.0$, and $L_{2} / R=10.0$

\begin{tabular}{|r|c|c|c|c|}
\hline$c$ & $\mathrm{Y}$ & $\mathrm{X}$ & $\rho$ & $\mu$ \\
\hline 45 & $*$ & $*$ & $*$ & $*$ \\
60 & 0.079 & 1.384 & $31^{\circ} 54^{\prime}$ & $22^{\circ} 42^{\prime}$ \\
75 & 0.220 & 1.316 & $39^{\circ} 11^{\prime}$ & $28^{\circ} 41^{\prime}$ \\
90 & 0.378 & 1.216 & $46^{\circ} 22^{\prime}$ & $35^{\circ} 50^{\prime}$ \\
105 & 0.536 & 1.084 & $53^{\circ} 33^{\prime}$ & $43^{\circ} 41^{\prime}$ \\
120 & 0.683 & 0.922 & $60^{\circ} 34^{\prime}$ & $52^{\circ} 6^{\prime}$ \\
135 & 0.810 & 0.731 & $67^{\circ} 57^{\prime}$ & $60^{\circ} 50^{\prime}$ \\
150 & 0.907 & 0.520 & $75^{\circ} 13^{\prime}$ & $69^{\circ} 41^{\prime}$ \\
165 & 0.966 & 0.316 & $82^{\circ} 36^{\prime}$ & $77^{\circ} 50^{\prime}$ \\
180 & 1.000 & 0.000 & $90^{\circ} 0$ & $90^{\circ} 0$ \\
\hline
\end{tabular}

*Data missing

\section{TABLE XV}

Parameter Set 13:

$L_{1}=10.0, L_{2}=10.0, R=0.75$,

$L_{1} / R=13.3$, and $L_{2} / R=13.3$

\begin{tabular}{|r|c|c|c|c|}
\hline$\alpha$ & $\mathrm{Y}$ & $\mathrm{X}$ & $\beta$ & $\mu$ \\
\hline 45 & $*$ & $*$ & $*$ & $*$ \\
60 & 0.029 & 1.050 & $32^{\circ} 45^{\prime}$ & $21^{\circ} 25^{\prime}$ \\
75 & 0.144 & 0.998 & $39^{\circ} 57^{\prime}$ & $27^{\circ} 26^{\prime}$ \\
90 & 0.269 & 0.922 & $47^{\circ} 2^{\prime}$ & $34^{\circ} 27^{\prime}$ \\
105 & 0.393 & 0.822 & $54^{\circ} 4^{\prime}$ & $43^{\circ} 3^{\prime}$ \\
120 & 0.507 & 0.699 & $61^{\circ} 4^{\prime}$ & $51^{\circ} 41^{\prime}$ \\
135 & 0.604 & 0.554 & $68^{\circ} 8^{\prime}$ & $60^{\circ} 30^{\prime}$ \\
150 & 0.678 & 0.396 & $75^{\circ} 19^{\prime}$ & $69^{\circ} 24^{\prime}$ \\
165 & 0.722 & 0.247 & $82^{\circ} 34^{\prime}$ & $77^{\circ} 24^{\prime}$ \\
180 & 0.750 & 0.000 & $90^{\circ} 0^{\prime}$ & $90^{\circ} 0$ \\
\hline
\end{tabular}

* Data missing
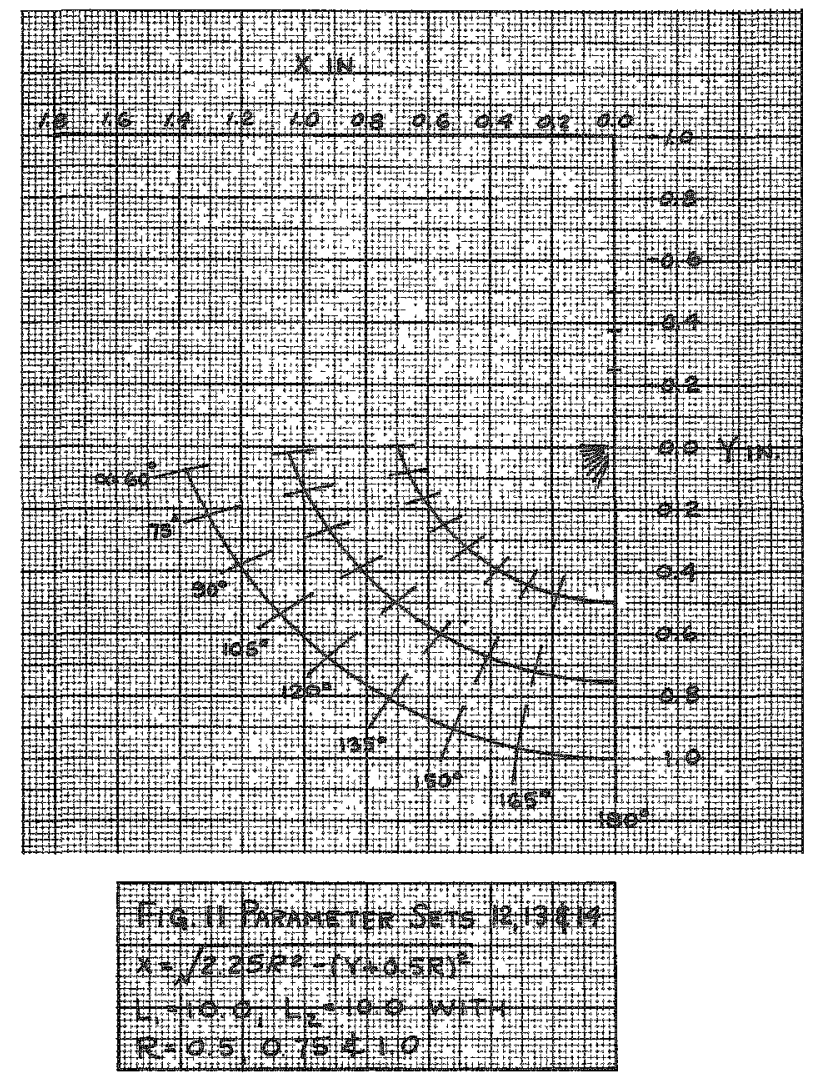
TABLE XVII

Parameter Set 15 .

$L_{1}=20.0, L_{2}=20.0, R=0.5$,

$L_{I} / R=40.0$, and $L_{2} / R=40.0$

\begin{tabular}{|c|c|c|c|c|}
\hline$a_{b}$ & $Y$ & $X$ & $\rho$ & $\mu$ \\
\hline 45 & * & $*$ & * & * \\
\hline 60 & $*$ & * & $*$ & * \\
\hline 75 & 0.068 & 0.679 & $38^{\circ} 22^{\prime}$ & $25^{\circ} 6$ \\
\hline 90 & 0.160 & 0628 & $45^{\circ} 41^{\prime}$ & $33^{\circ} 4^{\prime}$ \\
\hline 105 & 0.249 & 0560 & $53^{\circ} 1$ & $41^{\circ} 42^{\prime}$ \\
\hline 120 & 0330 & 0476 & $60^{\circ} 22^{\prime}$ & $50^{\circ} 37^{\prime}$ \\
\hline 135 & 0.398 & 0377 & $67^{\circ} 43^{\prime}$ & $59^{\circ} 48^{\prime}$ \\
\hline 150 & 0.449 & 0272 & $75^{\circ} 7$ & $68^{\circ} 44^{\prime}$ \\
\hline 165 & 0.478 & 0.179 & $82^{\circ} 33^{\prime}$ & $76^{\circ} 11^{\prime}$ \\
\hline 180 & 0.500 & 0.000 & $90^{\circ} 0^{\prime}$ & $90^{\circ} 0$ \\
\hline
\end{tabular}

* Data missing

TABLE XIX

Parameter Set 17

$L_{1}=20.0, L_{2}=20.0, R=20$,

$L_{1} / R=100$, and $L_{2} / R=10.0$

\begin{tabular}{|c|c|c|c|c|}
\hline$\gamma$ & $Y$ & $X$ & $\mu$ & $\mu$ \\
\hline 45 & $*$ & $*$ & $*$ & $*$ \\
60 & 0160 & 2.767 & $33^{\circ} 33^{\prime}$ & $22^{\circ} 45^{\prime}$ \\
75 & 0.443 & 2.630 & $40^{\circ} 43^{\prime}$ & $28^{\circ} 45^{\prime}$ \\
90 & 0.759 & 2.430 & $47^{\circ} 40^{\prime}$ & $35^{\circ} 54^{\prime}$ \\
105 & 1.076 & 2.166 & $54^{\circ} 32^{\prime}$ & $43^{\circ} 46^{\prime}$ \\
120 & 1.370 & 1.839 & $61^{\circ} 24^{\prime}$ & $52^{\circ} 1^{\prime}$ \\
135 & 1.624 & 1.454 & $68^{\circ} 20^{\prime}$ & $61^{\circ} 1^{\prime}$ \\
150 & 1.821 & 1.022 & $75^{\circ} 24^{\prime}$ & $70^{\circ} 5$ \\
165 & 1.943 & 0.583 & $82^{\circ} 38^{\prime}$ & $78^{\circ} 47^{\prime}$ \\
180 & 2.000 & 0.000 & $90^{\circ} 0$ & $90^{\circ} 0^{\prime}$ \\
\hline
\end{tabular}

* Data missing
TABLE XVIII

Parameter Set 10

$\mathrm{L}_{1}=20.0, \mathrm{~L}_{2}=200, \mathrm{R}=1.0$,

$\mathrm{L}_{\mathbb{1}} / \mathrm{R}=20.0$, and $\mathrm{L}_{2} / \mathrm{R}=20.0$

\begin{tabular}{|c|c|c|c|c|c|}
\hline & $\mathrm{Y}$ & & $x$ & & $\mu$ \\
\hline 45 & 水 & & $*$ & $*$ & * \\
\hline 60 & 0001 & & 414 & $31^{\circ} 53^{\prime}$ & $19^{\circ} 31^{\prime}$ \\
\hline 75 & 0.165 & 1 & 344 & $39^{\circ} 10^{\prime}$ & $26^{\circ} 20^{\prime}$ \\
\hline 90 & 0341 & 1 & 212 & $16^{\circ} 22^{\prime}$ & $34^{\circ} 4$ \\
\hline 105 & 0.512 & 1 & 107 & $53^{\circ} 32^{\prime}$ & $42^{\circ} 26^{\prime}$ \\
\hline 120 & 0670 & 0 & 938 & $60^{\circ} 42^{\prime}$ & $51^{\circ} 17^{\prime}$ \\
\hline 135 & 0804 & 0 & 741 & $67^{\circ} 56$ & $60^{\circ} 23^{\prime}$ \\
\hline 150 & 0.905 & & .525 & $75^{\circ} 13^{\prime}$ & $69^{\circ} 31^{\prime}$ \\
\hline 165 & 0900 & 0 & 318 & $82^{\circ} 35^{\prime}$ & $77^{\circ}+46^{\prime}$ \\
\hline 180 & 1000 & 0 & 000 & $90^{\circ} 0$ & $90^{\circ} 0^{\prime}$ \\
\hline
\end{tabular}

* Data missing
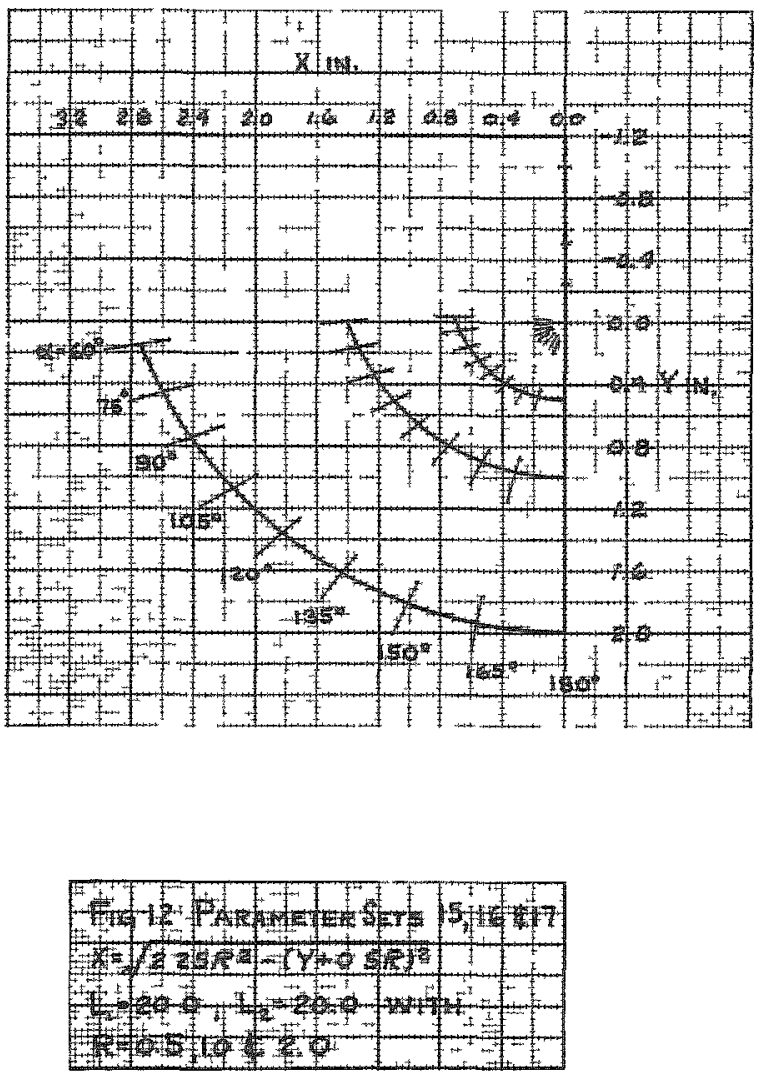
TABLE XX

Parameter Set 18:

$L_{1}=10.0, L_{2}=40.0, R=0.5$, $\mathrm{L}_{1} / \mathrm{R}=20$, and $\mathrm{L}_{2} / \mathrm{R}=80$

\begin{tabular}{|r|c|c|c|c|}
\hline$\alpha$ & $\mathrm{Y}$ & $\mathrm{X}$ & $\rho$ & $\mu$ \\
\hline 45 & $*$ & $*$ & $*$ & $*$ \\
60 & 0.000 & 0.707 & $31^{\circ} 38^{\prime}$ & $19^{\circ} 28^{\prime}$ \\
75 & 0.080 & 0.674 & $38^{\circ} 53^{\prime}$ & $26^{\circ} 5^{\prime}$ \\
90 & 0.167 & 0623 & $46^{\circ} 7^{\prime}$ & $33^{\circ} 48^{\prime}$ \\
105 & 0.253 & 0556 & $53^{\circ} 20^{\prime}$ & $42^{\circ} 8$ \\
120 & 0.332 & 0.472 & $60^{\circ} 34^{\prime}$ & $50^{\circ} 58^{\prime}$ \\
135 & 0.399 & 0.376 & $67^{\circ} 50^{\prime}$ & $59^{\circ} 55^{\prime}$ \\
150 & 0.449 & 0.271 & $75^{\circ} 10^{\prime}$ & $68^{\circ} 48^{\prime}$ \\
165 & 0.479 & 0.178 & $82^{\circ} 35^{\prime}$ & $76^{\circ} 15^{\prime}$ \\
180 & 0.500 & 0.000 & $90^{\circ} 0$ & $90^{\circ} 0^{\prime}$ \\
\hline
\end{tabular}

* Data missing

\section{TABLE XXII}

Parameter Set 20:

$L_{1}=40.0, L_{2}=40.0, R=2.0$,

$\mathrm{L}_{1} / \mathrm{R}=20.0$, and $\mathrm{L}_{2} / \mathrm{R}=20.0$

\begin{tabular}{|r|c|c|c|c|}
\hline & $\mathrm{Y}$ & $\mathrm{X}$ & $\rho$ & $\mu$ \\
\hline 45 & $*$ & $*$ & $*$ & $*$ \\
60 & 0.004 & 2.827 & $31^{\circ} 53^{\prime}$ & $19^{\circ} 27^{\prime}$ \\
75 & 0.333 & 2.688 & $39^{\circ} 10^{\prime}$ & $26^{\circ} 22^{\prime}$ \\
90 & 0.684 & 2.483 & $46^{\circ} 22^{\prime}$ & $34^{\circ} 9^{\prime}$ \\
105 & 1.028 & 2.211 & $53^{\circ} 32^{\prime}$ & $42^{\circ} 32^{\prime}$ \\
120 & 1.344 & 1.872 & $60^{\circ} 42^{\prime}$ & $51^{\circ} 25^{\prime}$ \\
135 & 1.613 & 1.475 & $67^{\circ} 55^{\prime}$ & $60^{\circ} 33^{\prime}$ \\
150 & 1.817 & 1.032 & $75^{\circ} 12^{\prime}$ & $69^{\circ} 53^{\prime}$ \\
165 & 1.942 & 0.586 & $82^{\circ} 34^{\prime}$ & $78^{\circ} 44^{\prime}$ \\
180 & 2000 & 0.000 & $90^{\circ} 0^{\prime}$ & $90^{\circ} 0^{\prime}$ \\
\hline
\end{tabular}

* Data missing
TABLE XXI

Parameter Set 19

$L_{1}=10.0, L_{2}=40.0, R=1.0$, $L_{1} / R=10$, and $L_{2} / R=40$

\begin{tabular}{|c|c|c|c|c|}
\hline & $Y$ & $\mathrm{X}$ & $r$ & $\mu$ \\
\hline 45 & * & * & $*$ & * \\
\hline 60 & 0075 & 1385 & $33^{\circ} 12^{\prime}$ & $22^{\circ} 33^{\prime}$ \\
\hline 75 & 0.215 & 1.319 & $40^{\circ} 15^{\prime}$ & $28^{\circ} 28^{\prime}$ \\
\hline 90 & 0.373 & 1.220 & $47^{\circ} 12^{\prime}$ & $35^{\circ} 35^{\prime}$ \\
\hline 105 & 0.532 & 1089 & $54^{\circ} \mathrm{g}$ & $43^{\circ} 28^{\prime}$ \\
\hline 120 & 0.080 & 0926 & $02^{\circ} 7$ & $51^{\circ} 53^{\prime}$ \\
\hline 135 & 0.808 & 0.734 & $68^{\circ} 10^{\prime}$ & $60^{\circ} \pm 2^{\prime}$ \\
\hline 150 & 0906 & 0.522 & $75^{\circ} 19^{\prime}$ & $69^{\circ} 38^{\prime}$ \\
\hline 165 & 0966 & 0.317 & $82^{\circ} 37^{\prime}$ & $77^{\circ} 48^{1}$ \\
\hline 180 & 1.000 & 0.000 & $90^{\circ} 0^{\prime}$ & $90^{\circ} 0$ \\
\hline
\end{tabular}

* Data missing
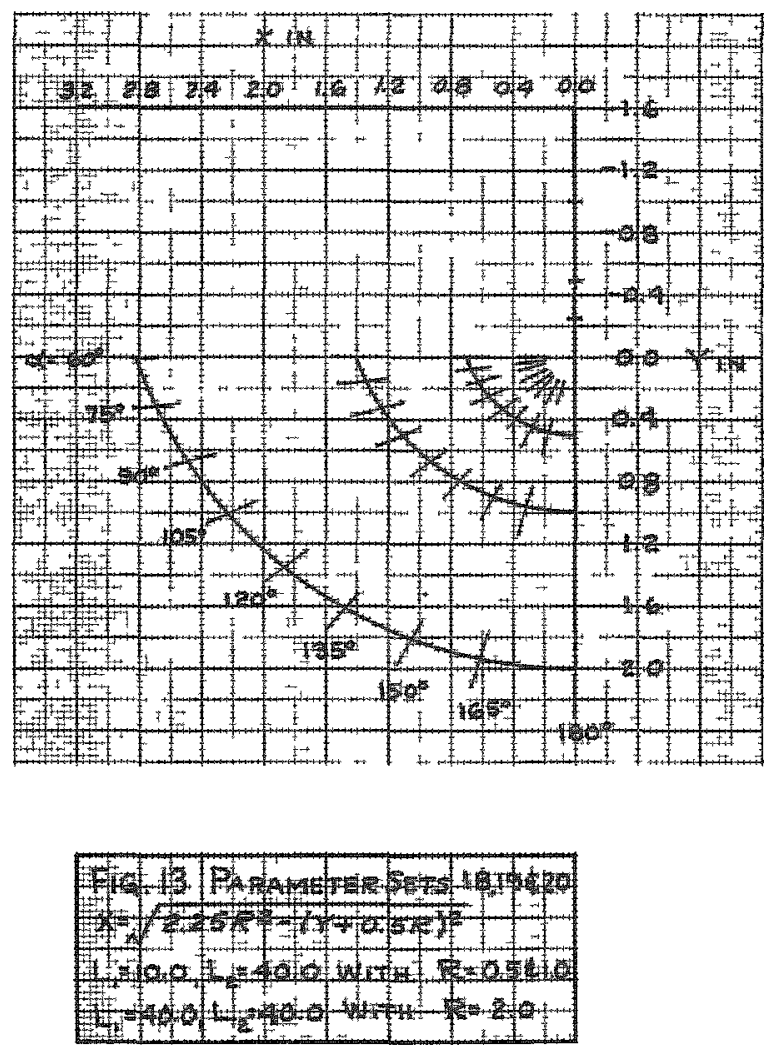
TABLE XXIII

Parameter Set 21

$L_{1}=10.0, L_{2}=200, R=0.5$,

$L_{1} / R=200$, and $L_{2} / R=400$

\begin{tabular}{|r|c|c|c|c|}
\hline \multicolumn{1}{|c|}{$*$} & $\mathrm{Y}$ & $\mathrm{X}$ & $\rho$ & $\mu$ \\
\hline 45 & $*$ & $*$ & $*$ & $*$ \\
60 & 0.000 & 0.707 & $31^{\circ} 43^{\prime}$ & $19^{\circ} 28^{\prime}$ \\
75 & 0.080 & 0.673 & $38^{\circ} 59^{\prime}$ & $26^{\circ} 20^{\prime}$ \\
90 & 0.168 & 0.623 & $46^{\circ} 12^{\prime}$ & $33^{\circ} 51^{\prime}$ \\
105 & 0.254 & 0.556 & $53^{\circ} 24^{\prime}$ & $42^{\circ} 12^{\prime}$ \\
120 & 0.333 & 0.472 & $60^{\circ} 37^{\prime}$ & $51^{\circ} 1^{\prime}$ \\
135 & 0.399 & 0.375 & $67^{\circ} 52^{\prime}$ & $59^{\circ} 59^{\prime}$ \\
150 & 0.449 & 0.271 & $75^{\circ} 11^{\prime}$ & $68^{\circ} 49^{\prime}$ \\
165 & 0.479 & 0.178 & $82^{\circ} 34^{\prime}$ & $76^{\circ} 16^{\prime}$ \\
180 & 0.500 & 0.000 & $90^{\circ} 0$ & $90^{\circ} 0$ \\
\hline
\end{tabular}

* Data missing
TABLE XXIV

Parameter Set 22

$L_{1}=100, L_{2}=200, R=10$,

$L_{1} / R=100$, and $L_{2} / R=200$

\begin{tabular}{|r|c|c|c|c|}
\hline & $\mathrm{Y}$ & $\mathrm{X}$ & $\mathrm{i}$ & $\mu$ \\
\hline 45 & $*$ & $*$ & $*$ & $*$ \\
00 & 0076 & 1385 & $33^{\circ} 19^{\prime}$ & $22^{\circ} 35^{\prime}$ \\
75 & 0.216 & 1318 & $40^{\circ} 24^{\prime}$ & $28^{\circ} 31^{\prime}$ \\
90 & 0.374 & 1219 & $47^{\circ} 22^{\prime}$ & $35^{\circ} 39^{\prime}$ \\
105 & 0.533 & 1088 & $54^{\circ} 13^{\prime}$ & $43^{\circ} 31^{\prime}$ \\
120 & 0.081 & 0.924 & $61^{\circ} 12^{\prime}$ & $51^{\circ} 58^{\prime}$ \\
135 & 0.809 & 0.733 & $68^{\circ} 13^{\prime}$ & $60^{\circ} 45^{\prime}$ \\
150 & 0.906 & 0.522 & $75^{\circ} 21^{\prime}$ & $69^{\circ} 40^{\prime}$ \\
105 & 0906 & 0317 & $82^{\circ} 38^{\prime}$ & $77^{\circ} 48^{\prime}$ \\
180 & 1.000 & 0.000 & $90^{\circ} 0$ & $90^{\circ} 0$ \\
\hline
\end{tabular}

* Data missing
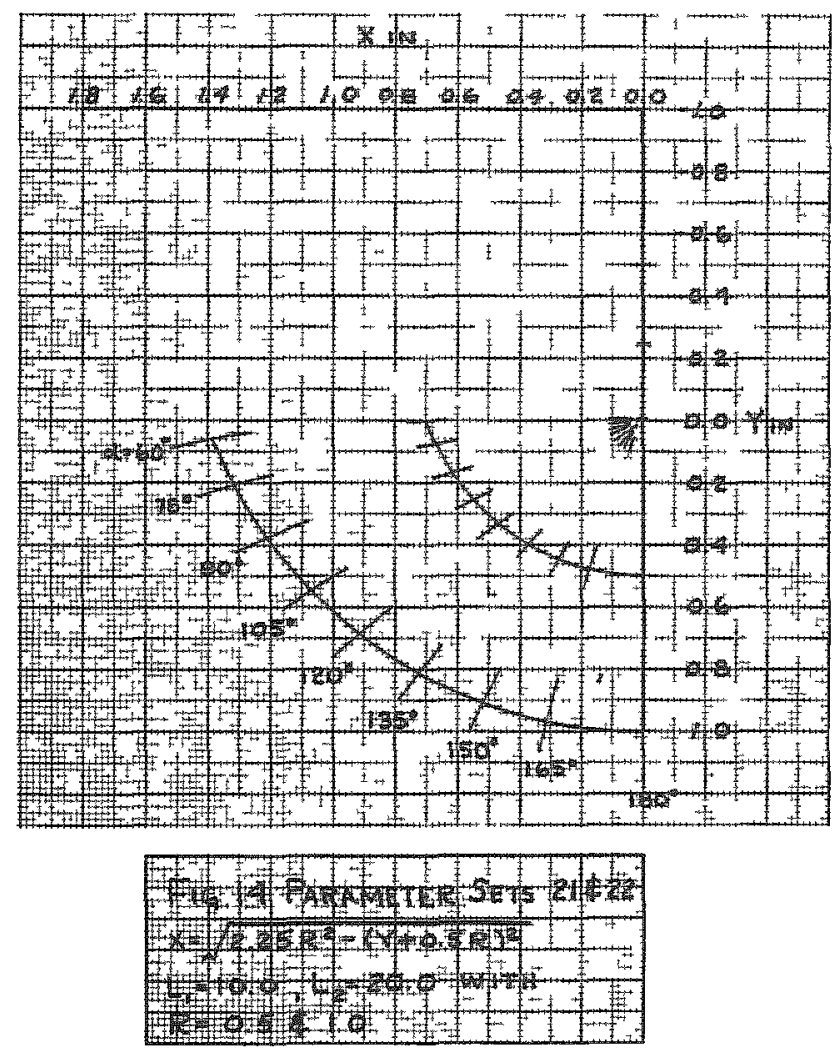
TABLE XXV

Parameter Set 23:

$L_{1}=30.0, L_{2}=30.0, R=1.0$, $L_{1} / R=30.0$, and $L_{2} / R=30.0$

\begin{tabular}{|r|c|c|c|c|}
\hline$x$ & $\mathrm{Y}$ & $\mathrm{X}$ & $\rho$ & $\mu$ \\
\hline 45 & $*$ & $*$ & $*$ & $*$ \\
60 & $*$ & $*$ & $*$ & $*$ \\
75 & 0.147 & 1.353 & $38^{\circ} 37^{\prime}$ & $25^{\circ} 33^{\prime}$ \\
90 & 0.328 & 1.251 & $45^{\circ} 55^{\prime}$ & $33^{\circ} 30^{\prime}$ \\
105 & 0.505 & 1.114 & $53^{\circ} 12^{\prime}$ & $42^{\circ} 4^{\prime}$ \\
120 & 0.666 & 0.944 & $60^{\circ} 29^{\prime}$ & $51^{\circ} 1^{\prime}$ \\
135 & 0.802 & 0.745 & $67^{\circ} 47^{\prime}$ & $60^{\circ} 13^{\prime}$ \\
150 & 0.905 & 0.527 & $75^{\circ} 9^{\prime}$ & $69^{\circ} 26^{\prime}$ \\
165 & 0.966 & 0.318 & $82^{\circ} 33^{\prime}$ & $77^{\circ} 46^{\prime}$ \\
180 & 1.000 & 0.000 & $90^{\circ} 0$ & $90^{\circ} 0$ \\
\hline
\end{tabular}

* Data missing
TABLE XXVI

Parameter Set. 24:

$L_{1}=30, L_{2}=40, R=1.0$,

$L_{1} / R=30$, and $L_{2} / R=40$

\begin{tabular}{|c|c|c|c|c|}
\hline & $Y$ & $X$ & $p$ & $\mu$ \\
\hline 45 & $*$ & $*$ & $*$ & $*$ \\
60 & $*$ & $*$ & $*$ & $*$ \\
75 & 0.116 & 1.354 & $38^{\circ} 33^{\prime}$ & $25^{\circ} 31^{\prime}$ \\
90 & 0.327 & 1.251 & $45^{\circ} 51^{\prime}$ & $33^{\circ} 28^{\prime}$ \\
105 & 0.504 & 1.114 & $53^{\circ} 9^{\prime}$ & $42^{\circ} 2$ \\
120 & 0.605 & 0.944 & $60^{\circ} 27^{\prime}$ & $50^{\circ} 59^{\prime}$ \\
135 & 0.802 & 0.745 & $67^{\circ} 46^{\prime}$ & $60^{\circ} 13^{\prime}$ \\
150 & 0.904 & 0.527 & $75^{\circ} 8^{\prime}$ & $69^{\circ} 25^{\prime}$ \\
165 & 0.966 & 0.318 & $82^{\circ} 33^{\prime}$ & $77^{\circ} 48^{\prime}$ \\
180 & 1.000 & 0.000 & $90^{\circ} 0$ & $90^{\circ} 0$ \\
\hline
\end{tabular}

* Data missing
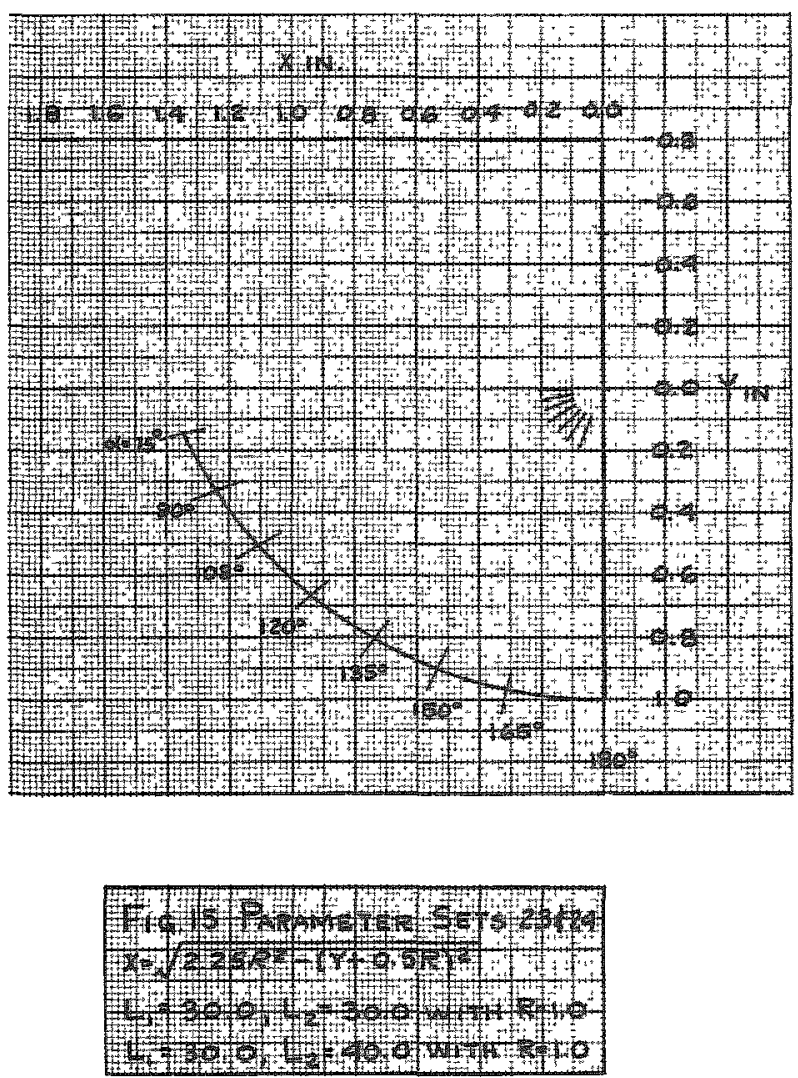


\section{Summary}

A review of the results obtained for the Parameter Sets of Table XIII can best be obtained from the tabular data. This differs from results of the Particular Solution $A$, which were mainly evident on the graphical presentation. The reason for this difference is that with the Particular Solution A the path of the point $O$ was laid out. In Particular Solution $B$ the path is already known, but the points on the path are undetermined.

Of the ten Parameter Sets of Table I, eight were duplicated in Table XIII. Five additional parameter sets were also used as inputs for Eq. 48. Duplication allowed comparison between Particular Solutions A and B. The comparison resulted in a comparative path but a difference in position on the path.

Although the program for Particular Solution B was similar to that for Particular Solution A, difficulty in obtaining a solution was encountered. This was found to be caused by terms under radical signs becoming negative. Physically meaningless answers were obtained, since the program used the absolute value of all terms whose roots were taken. A comparison of the radical terms with the graphical solution obtained with the first (or tangential) relationship showed that, if the point for a given angle fell outside of the circular arc, certain radicals became negative. The points that fell outside of the circular arc were for values of $\alpha$ equal to 15 and 30 degrees. When $\alpha$ was equal to 45 degrees, conditions were marginal.

Due to these marginal conditions, the program was revised to start with $\alpha=60$ degrees. This seemed to solve the difficulties, since solutions were obtained for eleven sets of parameters: however, the other three gave erratic results again. The sets of parameters which failed to give a solution with $\alpha$ starting at 60 degrees are:

\begin{tabular}{|c|c|c|c|c|c|}
\hline $\begin{array}{c}\text { Parameter } \\
\text { Set }\end{array}$ & $\mathrm{L}_{\mathrm{I}}$ & $\mathrm{L}_{2}$ & $\mathrm{R}$ & $\mathrm{L}_{\mathbb{I}} / \mathrm{R}$ & $\mathrm{L}_{\mathrm{Z}} / \mathrm{R}$ \\
\hline 15 & 20.0 & 20.0 & 0.5 & 40.0 & 40.0 \\
23 & 30.0 & 30.0 & 1.0 & 30.0 & 30.0 \\
24 & 30.0 & 40.0 & 1.0 & 30.0 & 40.0 \\
\hline
\end{tabular}

A comparison of these parameters with those that gave solutions showed that somewhere between $L_{\mathbb{I}} / R=20.0$ and $L_{\mathbb{I}} / R=30.0$ there is a change to the imaginary zone.

The first attack was to start at $\alpha=75$ degrees. This resulted in a solution for all three sets. This, as well as starting the other sets at 60 degrees, does not satisfy the needs of a manipulator to obtain values of $\alpha=45$ degrees. Further investigation into the error in cable length has shown that, for $\alpha=45$ degrees, $L_{\mathbb{I}} / R=10.0$ and $Y=0.0$, Eq. 56 is satisfied. 
For $\alpha=45$ degrees, the error varies from 0.000 in. for $L / R=10.0$ to $0.023 \mathrm{in}$. at $\mathrm{L}_{\mathrm{I}} / \mathrm{R}=20.0$ and $0.47 \mathrm{in}$. at $\mathrm{L}_{\mathrm{J}} / \mathrm{R}=30.0$. The degree of error was obtained by a slight revision to the program. which eliminated the trial-and-error portion.

The program for calculating the length of cable is very valuable, since it can be used to determine deviations from the true path which can be tolerated. This tolerance had been assumed to be 0.001 in. for use in computing the solutions to Tables I and XIII. The method used for solving a four -bar linkage involves the use of four or five precision points; the variation between points may cause a change in length which may or may not be acceptable. The program for computing length easily determines this variation. Also, in the case of a single link, this variation can be found when a line parallel to the link bisects the included angle between the lines JK and MN.

The amount of allowable variation is dependent on the length and size of cable: the longer the cable, the greater the tolerance, and the larger the cable, the greater the tolerance.

\section{DESIGN OF MANIPULATOR MECHANISM}

In addition to the information obtained during this investigation, data with regard to the physical properties of the cables or tapes are also neces sary in order to design a working mechanism. At this point, the word tape is introduced in addition to cables. Either may be used in an actual mechanism, and both satisfy the conditions used during the solution of the pulley center path. Cables have the advantage of changing directions in more than one plane, along with a lower bending stress in the cables for a given pulley size. The tapes are restricted to changing direction in a single plane where short arm lengths are involved. The tapes have the advantages of less friction and of less deflection.

The type of cable used for most manipulator designs is of the $7 \times 19$ construction. There is one exception, since $3 \times 7$ is used for $\frac{1}{32}-i n$. diameter cable. The cables are usually stainless steel. The tapes are of two sizes: $\frac{3}{16}$ in. wide by $0.005 \mathrm{in}$. thick, or $\frac{1}{4} \mathrm{in}$. wide by $0.010 \mathrm{in}$. thick. The tapes are made from Elgiloy, the trade name for a cobalt, chromium, nickel and molybdenum alloy manufactured by the Elgin National Watch Company of Elgin, Illinois. An experimental lot of $\frac{3}{6}$ in. diameter cable has also been made using Elgiloy.

There is a desirable relationship between cable or tape size and pulley size, since the bending stress in the cable is directly proportional to the pulley diameter. If the diameter of the pulley is 32 times the cable diam. eter, the bending stress is approximately 10 to 15 per cent of the ultimate stress for $7 \times 19$ cables. For $3 \times 7$ cables, the hending stress becomes 20 per cent. With tapes, the pulley diameter is 400 times the tape thickness: 
this gives a bending stress of approximately 25 to 30 per cent of the ultimate stress. The relationship for tapes was based on the equal pulley size for equal deflection when compared to a $\frac{1}{16}-i n$. diameter cable. The relations for pulley size are minimum recommendations. A large pulley is preferable since in addition to a lower stress, a large pulley reduces friction. Friction becomes additive for each pulley, while the maximum bending stress is obtained only at the smallest pulley.

One approximate load on the cables due to loading the manipulator is four times the specified load. For example, a 50-pound manipulator will usually have cables loaded to 200 pounds. A comparison of the load capacity of the various cables and tapes used in manipulator design, and their relative deflections, are given in Table XXVII. The recommended pulley size and load due to bending are included.

TABLE XXVII

Load Capacities and Relative Deflections of Cables and Tapes

\begin{tabular}{|l|c|c|c|c|}
\hline $\begin{array}{c}\text { Cable } \\
\text { Diameter, } \\
\text { in. }\end{array}$ & $\begin{array}{c}\text { Ultimate } \\
\text { Strength, } \\
\text { lb }\end{array}$ & $\begin{array}{c}\text { Deflection } \\
\text { in. } \\
(100 \mathrm{Lb}, 6 \mathrm{ft} \mathrm{lg})\end{array}$ & $\begin{array}{c}\text { Pulley } \\
\text { Diameter, } \\
\mathrm{n} .\end{array}$ & $\begin{array}{c}\text { Bending } \\
\text { Load, } \\
\mathrm{lb}\end{array}$ \\
\hline $0.032\left(\frac{1}{32}\right)$ & 120 & 1 & 1.000 & 24 \\
$0.045\left(\frac{3}{64}\right)$ & 215 & $\frac{3}{8}$ & 1.500 & 22 \\
$0.070\left(\frac{1}{16}\right)$ & 480 & $\frac{1}{4}$ & 2.000 & 06 \\
$0.100\left(\frac{3}{32}\right)$ & 1000 & $\frac{1}{8}$ & 3.000 & 120 \\
$0.135\left(\frac{1}{8}\right)$ & 1900 & $\frac{1}{16}$ & 4.000 & 220 \\
Tape Size & & $\frac{1}{4}$ & & \\
\hline $0.188 \times 0.005$ & 250 & $\frac{1}{8}$ & 4.000 & 188 \\
$0.250 \times 0.010$ & 025 & & & \\
\hline
\end{tabular}

The ultimate strength and deflections were found from tests. These check with calculated and published data within test accuracy. The bending load was calculated from the following formulas:

$$
S_{b}=E_{c} d_{w} / D_{p}
$$

where

$$
\begin{aligned}
& \mathrm{S}_{\mathrm{b}}=\text { bending stress in outer wire, psi } \\
& \mathrm{E}_{\mathrm{C}}=\text { modulus of elasticity of cable or tape, psi } \\
& \mathrm{d}_{\mathrm{W}}=\text { diameter of wire, in. } \\
& \mathrm{D}_{\mathrm{p}}=\text { pulley diameter, in. }
\end{aligned}
$$


The equivalent bending load in pounds is

$$
F_{b}=A_{c} S_{b}=\frac{A_{c} E_{c} d_{w}}{D_{p}},
$$

where

$$
A_{C}=\text { Area of cable, in }{ }^{2} \text {. }
$$

The diameter of wire can be found in two ways. One is to simply measure a sample; the other is based on geometrical construction which gives the following relationships between the diameter of the cable, $d_{c}$, and the diameter of the wire. The area of a cable can also be obtained geometrically.

$$
\begin{aligned}
& 7 \times 19 \text { cable }-d_{w}=0.066 d_{c} \\
& 7 \times 19 \text { cable }-A_{c}=0.45 d_{c}^{2} \\
& 3 \times 7 \text { cable }-d_{w}=0.156 d_{c} \\
& 3 \times 7 \text { cable }-A_{c}=0.40 d_{c}^{2} .
\end{aligned}
$$

Based on Table XXVII and the relationship between manipulator capacity and cable load, the computation of permissible load due to items other than load and bending stress, such as the forces due to stopping or starting, the force equivalent for wear, pre-tension in the cable, and most particularly the amount permissible for change in length due to possible variation from the prescribed paths, is possible. In addition to the foregoing, there should be a safety allowance to account for possible variations in physical properties of the cables or tapes. In manipulator design, there are also changes of length due to temperature or rotation out of a flat plane. The temperature change may be neglected, since usually the temperature difference is limited to 40 degrees. The change in length due to rotation out of a flat plane must be subtracted from any permissible change in length for a prescribed pulley center path. This change in length could range from $0.049 \mathrm{in}$ to $0.198 \mathrm{in}$. for $L_{2}=10.0 \mathrm{in.}$, depending on pulley size. If $L_{2}$ increases to $40.0 \mathrm{in}$, the change in length is from $0.012 \mathrm{in}$. to $0.050 \mathrm{in}$. for the same variation in pulley size.

The per cent of ultimate load for each of the above items approaches constant values for cables or tapes. The size of the cable or tape has little effect on the magnitude of this per cent of ultimate for eachitem. Table XXVIII shows these various percentages.

The loads due to the manipulator are based on present manipulator designs. The loads due to bending are based on the pulley diameters of Table XXVII. Load due to acceleration can only be estimated, but it must be accounted for, since all power to the cables and tapes of electronically 
TABLE XXVIII

Percentages of Ultimate Load for Cables and Tapes

\begin{tabular}{|l|c|c|}
\hline \multicolumn{1}{|c|}{ Type of Load } & $\begin{array}{c}\text { \% of Ultimate } \\
\text { Load for Cables }\end{array}$ & $\begin{array}{c}\text { \% of Ultimate } \\
\text { Load for Tapes }\end{array}$ \\
\hline Manipulator & 37 & 28 \\
Bending & 13 & 27 \\
Acceleration & 5 & 5 \\
Wear & 10 & 5 \\
Change in Length & 25 & 25 \\
Safety Allowance & 10 & 10 \\
\multicolumn{1}{|c|}{ TOTAL } & 100 & 100 \\
\hline
\end{tabular}

controlled manipulators is provided by high-accelerating, quick-reversing servo-motors. The difference between cable and tape wear is because the internal and pulley friction are much greater for cables, thus resulting in more wear. Overlooking the change in length, the allowance is needed for variations in physical properties of materials. Although the change in length has the same percentage for cables and tapes, the amount of deflection is more for cables. A deflection of $0.0050 \mathrm{in}$. per inch of length can be tolerated for cables; a deflection of $0.0021 \mathrm{in}$. per inch of length can be tolerated for tapes. The difference is due to the apparent modulus of elasticity of the cable.

The change in length consists of initial tension, rotation out of plane and deviation from a prescribed path. This change in length ranges between $0.100 \mathrm{in}$. and $0.400 \mathrm{in}$. for cables, and between $0.042 \mathrm{in.}$ and $0.168 \mathrm{in}$. for tapes. The amount of initial tension is dependent on physical take-up and anticipated temperature variations. For the purpose of this investigation, temperature effects were neglected, since the temperature is approximately constant during use. An initial tension of approximately 3 per cent of ultimate has proved satisfactory to date. This reduced the allowable deflection by $0.0006 \mathrm{in}$. per inch for cables, and by $0.00025 \mathrm{in}$. per inch for tapes.

In order to get some feel for the problems involved in design of the actual mechanism, assume that the change in length due to rotation out of plane is an average value of $0.155 \mathrm{in.}$ With this value, only very long tapes could be used, or the amount of rotation out of plane would have to be restricted. This value would also eliminate most of the very short-arm manipulators. With tapes, rotation out of plane is not as common as with cables; hence, this problem is not as serious as it looks. With cables, however, it means that for very short-arm manipulators, small size pulleys or restriction of rotation must be incorporated. This portion of the design is straightforward, and the best case for each manipulator can be obtained easily. Neglecting this part of the design, but making allowance for the 
magnitude of its change, a figure of ten per cent of ultimate for deviation from a prescribed path becomes feasible.

Ten per cent means a tolerable limit of $0.002 \mathrm{in}$. per inch of cable length or 0.0008 in. per inch of tape length. This means a manipulator having two 10 -inch arms may have a deviation of 0.040 in., while one with two 40 -inch arms may have a deviation of $0.160 \mathrm{in.}$ For tapes, these values would be $0.016 \mathrm{in}$. and $0.064 \mathrm{in}$. respectively. This means that, for shorter arms, the use of a single link solution becomes impossible, since the deviation needed approaches $0.055 \mathrm{in}$. This also eliminates the use of a single link for a solution with tapes. Figure 16 shows a possible design of a single link system.

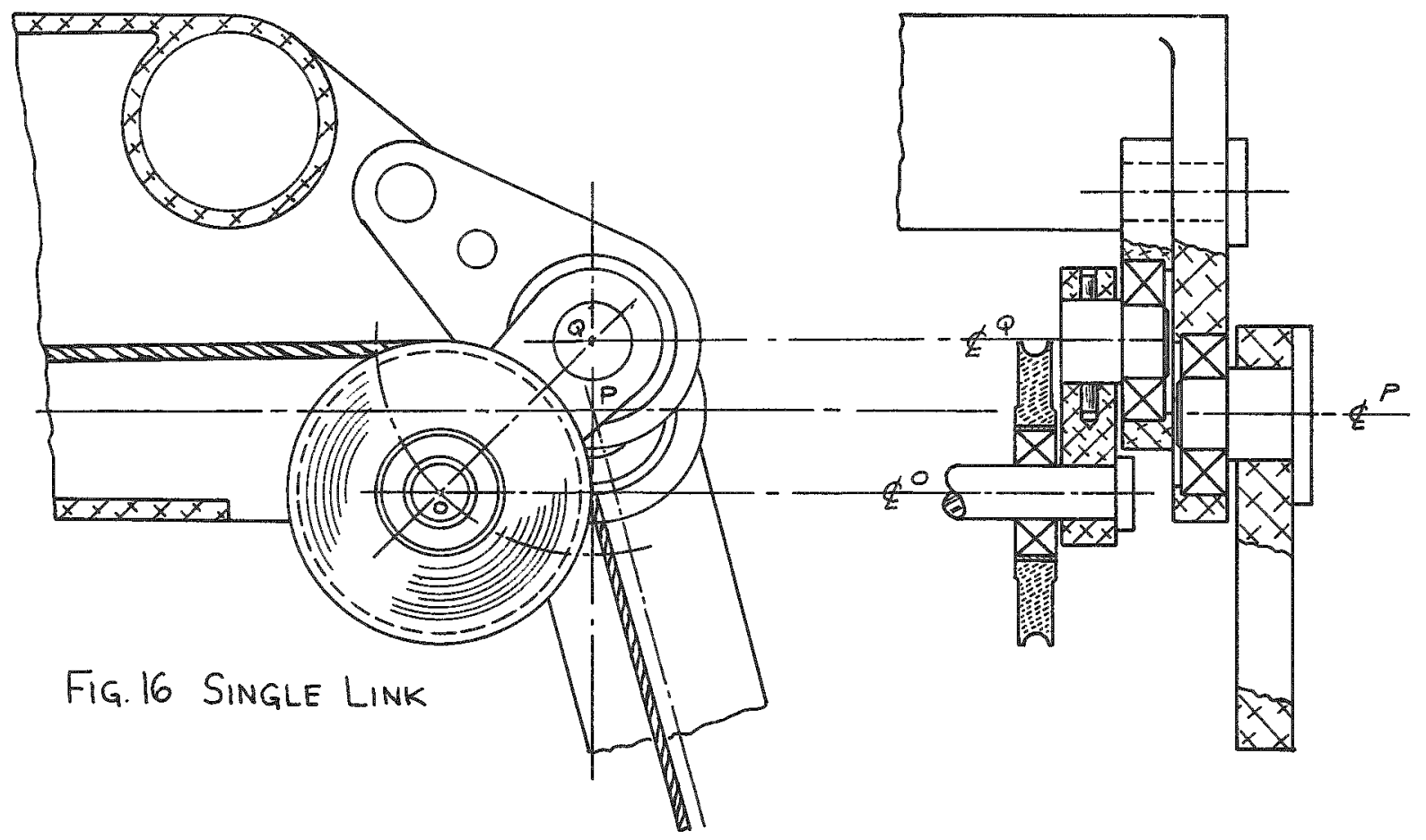

The single link as shown in Fig. 16 would work for a pair of 20 -inch or longer arms. This solution would, however, be limited to 45 to 180 degrees of motion, since, when using a single link, its length would have to be equal to $2 \mathrm{R}$ in order to have one pulley clear the other. This is needed for symmetrical operation to 315 degrees. The additional link to which the point $Q$ is mounted is a feature needed for remote replacement of broken cables. During operation of the manipulator, this link acts as part of the upper arm, $\mathrm{L}_{1}$. During cable replacement, this link pivots, giving slack to the cable.

Figure 17 shows a possible "straight-cam" solution. This solution was suggested by Professor Denavit from preliminary data obtained. This could be a very good solution for the short-arm or tape manipulators which need exact solutions. A link to slacken the cable is also present. This system 
would need additional design consideration to the problems of remote repair. Remote repair is an important item for all electronically controlled manipulators since, once in a shielded facility, they are never removed. All servicing must be by other manipulators or through neoprene gloves.

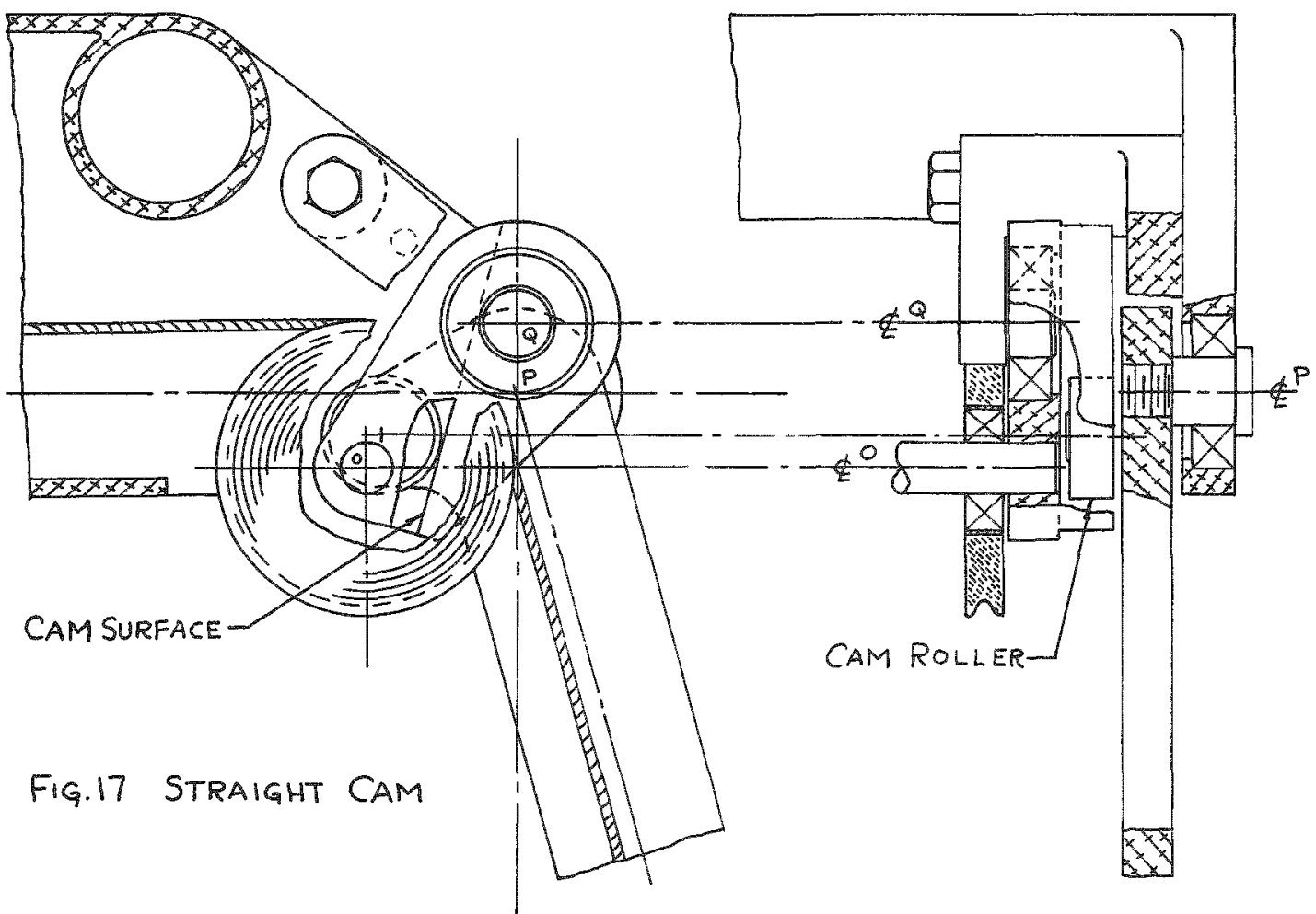

Figure 18 shows a schematic of four-bar linkage which gives a very close approximation to the exact solution. This scheme and that involving the straight cam are limited to a maximum of 180 degrees, like the single link. Figure 18(a) shows an intermediate position, whereas Fig. 18(b) shows the 180-degree position.

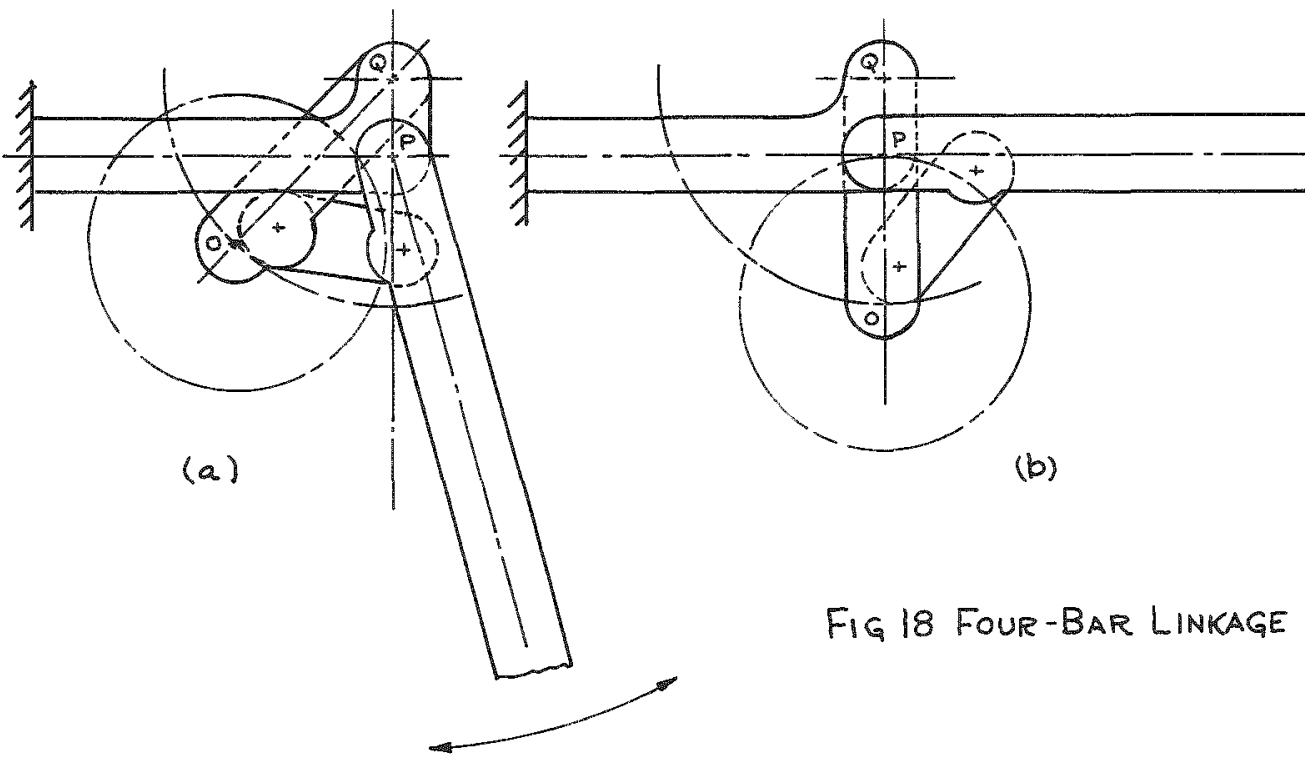


In addition to the solutions presented, there are a multitude of cam (exact) solutions to either of the two particular solutions obtained here. Heavy and expensive to build, they will not be discussed.

\section{CONCLUSIONS}

The purpose of this investigation was to find a general solution for the path of a pulley center giving a constant cable length while the cable changes direction over the pulley. The involved relations were solved by an IBM 650 digital computer. A solution for the path for any manipulator, given the lengths of the arms and pulley size, can be obtained in forty minutes from the programs developed. The solutions allow a variation of $\alpha$ between 45 and 315 degrees: practical design limitations hold $\alpha$ between 45 and 180 degrees. Further investigation to different relationships between $X$ and $Y$ may result in a design which would allow the complete travel.

Based on weight and cost, the single link is the best solution. Limitation to manipulators having long arms and cables eliminates the single link as a general solution. The relationship between $X$ and $Y$ could be changed by increasing the length of the single link and moving its pivot cen ter from the point directly above the arm. The amount of movement depends on the length of the single link, which in turn is dependent on the angle $\mu$ approaching $\rho$. The movement of the single alink pivot would be away from the arm pivot in the quadrant for which $X$ and $Y$ are negative. A longer link would allow greater angles of $\alpha$. As $\mu$ approaches $\rho$, manipulators having shorter arms or those using tapes may use the single link, thus approaching a general solution.

The use of a digital computer for manipulator kinematics has shown the way to other problems encountered. For example, a linkage system which could be used to balance a manipulator for greater angles of $\alpha$ may become practical. To date, the only approach to such a system has been an electronic one, and this is expensive. 


\section{APPENDIX A}

Bell $L_{1}$ Computer System

Use of the IBM 650 digital computer necessitates the need for a programming system since machine language, although faster, is more difficult to program for engineering problems. The system commonly known as the Bell $L_{1}$ system was used.

The Bell $L_{1}$ system is a floating point system; this indicates the decimal point of a number by a characteristic number similar to the characteristic number used for logarithms. The two-digit characteristic follows the eight-digits of number. Since the base characteristic is 50 , this allows a range of 0 to 99. A characteristic of 50 indicates a number $A_{I}$ for which the following is true: $1.0 \leq A_{1}<10$.

If the characteristic is 51 , then $10 \leq A_{1}<100$; if the characteristic is 49 , then $0.1 \leq A_{I}<1.0$, etc.

In addition to numbers as such, the system's instructions are signed ten-digit numbers. The instructions have the following form:

\begin{tabular}{|l|l|l|l|l|}
\hline \pm & $O_{1}$ & $A$ or $O_{2}$ & $B$ & $C$ \\
\hline
\end{tabular}

$O_{1}$ is a one-digit operation code and $B$ and $C$ are three-digit addresses. $A$ or $O_{2}$ is also interpreted as a three-digit address if $O_{1} \neq 0$. If $O_{1}=0$, then $\mathrm{O}_{2}$ is used as an operational code of three digits. A summary of these operational codes may be found in Table XXIX.

Using this system, the part of the program which covers the equation is straightforward. The remaining part of the program requires the setting up of repeating loop systems; they, upon reading in a value for $Y$, will decide if the value for $Y$ satisfies the equation. If it does, the answers are punched out; if not, a new value for $Y$ is selected and tried. This process is repeated for each value of $Y$ until it satisfies the equations. In addition to the trial and-error loop for $Y$, loops were needed to add increments to obtain 15 degree increments automatically. With the solution of more than one set of parameters, a loop to call for a new problem read-in was also incorporated.

The programs and loop-flow diagrams for each of the two particular solutions follow. In addition to the program shown, the program for Particular Solution B was used by changing one card and eliminating the trial-anderror loop in order to calculate the length of cable for a given value of $Y$. This allowed a comparison with the solutions of constant length to determine amounts of variation in length which may be tolerated. This is very important during the design of the mechanism, since it allows certain deviations which might permit the use of simpler mechanisms. 
TABLE XXIX

Summary of Operation Codes

\begin{tabular}{|c|l|l|l|l|l|}
\hline \multicolumn{2}{|c|}{ OI $_{1}$ Operations } & \multicolumn{4}{|c|}{ O $_{2}$ Operations } \\
\hline Num. & Alpha & Num. & Alpha & Num. & Alpha \\
\hline \multirow{2}{*}{0} & GO to O & 000 & UNC STOP & 350 & ABS \\
1 & ADD & 200 & COND STOP & 351 & EXP 10 \\
2 & SUB & 201 & TR SGN & 352 & LOG 10 \\
3 & MPY & 202 & TR EXP & 353 & SIN Degrees \\
4 & DIV & 203 & TR & 354 & COS Degrees \\
5 & NGMPY & 204 & TR SUBR & 355 & ART Degrees \\
6 & TR A & 205 & TR OUT & 400 & READ \\
7 & TR B & 300 & SQRT & 401 & CONS \\
8 & TR C & 301 & EXP E & 410 & PCH \\
9 & MOVE & 302 & LOG E & 450 & START TR \\
& & 303 & SIN Radians & 451 & STOP TR \\
& & 304 & COS Radians & 452 & ST TR ERAS \\
& & 305 & ART Radians & 454 & NOOP \\
\hline
\end{tabular}




\begin{tabular}{|c|c|c|c|c|c|c|c|}
\hline 500 & 0400400411 & 0400100111 & 0451000000 & 0354104060 & 0353104061 & 0450000000 & \\
\hline 506 & 4060061200 & 4401061201 & 5105200300 & 5102201301 & 1000100302 & 1000300302 & \\
\hline 512 & 3302302303 & 3105105305 & 3102102306 & 1303305307 & 2307306308 & 0451000000 & \\
\hline 513 & 0300303107 & 0450000000 & 0454000000 & 0451000000 & 0200307311 & 0450000000 & \\
\hline $52 t_{7}$ & 2102105312 & 4000311313 & 2000402314 & 9001313110 & 9001314111 & 2403104315 & \\
\hline 530 & $4000 l_{103315}$ & 3000402.315 & 1000313316 & 3000102103 & 3301301350 & 3105201353 & 3 \\
\hline 536 & 2101353354 & 3000000355 & 5102200356 & 1000000357 & 3000354358 & 2000306359 & $\stackrel{0}{3}$ \\
\hline 542 & 1000355360 & 1000350362 & 0451000000 & 0300000109 & 0450000000 & 1107108364 & $0_{2}^{7}$ \\
\hline 542 & 1000139365 & 1100101366 & 1407407000 & 0201552577 & 2366365367 & 0350000370 & 吾 \\
\hline 554 & 2000409360 & 0201502556 & $2100302100^{\circ}$ & 0410100111 & 9001410103 & 1404104104 & $\because \frac{0}{x}$ \\
\hline 560 & $2 \cdot 05104000$ & 0201502501 & 1367400367 & 0201564560 & 5103401369 & 0203000567 & $\frac{2}{2} \infty$ \\
\hline 506 & 9001103369 & 2370401000 & 0201569572 & 0451000000 & 0300370370 & 0450000000 & $\mathscr{0}$ \\
\hline $5 / 2$ & $43 / 036937$ & 9001105372 & 1372371105 & 5401401407 & 0203000508 & 2366365374 & $\overrightarrow{0}$ \\
\hline 578 & 0350374.375 & 0350367376 & 2376375371 & 0201589582 & 1401103103 & 0410102111 & $D$ \\
\hline 534 & 0203000536 & 0203000536 & 9001372105 & 3407407407 & 0203000503 & 2375409331 & \\
\hline 590 & 0201591556 & 3407407407 & 2410401430 & 4401430000 & 2103000103 & 0203000508 & \\
\hline 500 & $*$ & $\therefore$ & : & $\%$ & $\approx$ & $*$ & \\
\hline 400 & 2000000050 & 1000000050 & 1000000019 & 1300000052 & 1500000051 & 1700000052 & \\
\hline 406 & 0000000000 & 1000000050 & 3141592650 & 1000000047 & 5000000050 & 0000000000 & \\
\hline
\end{tabular}




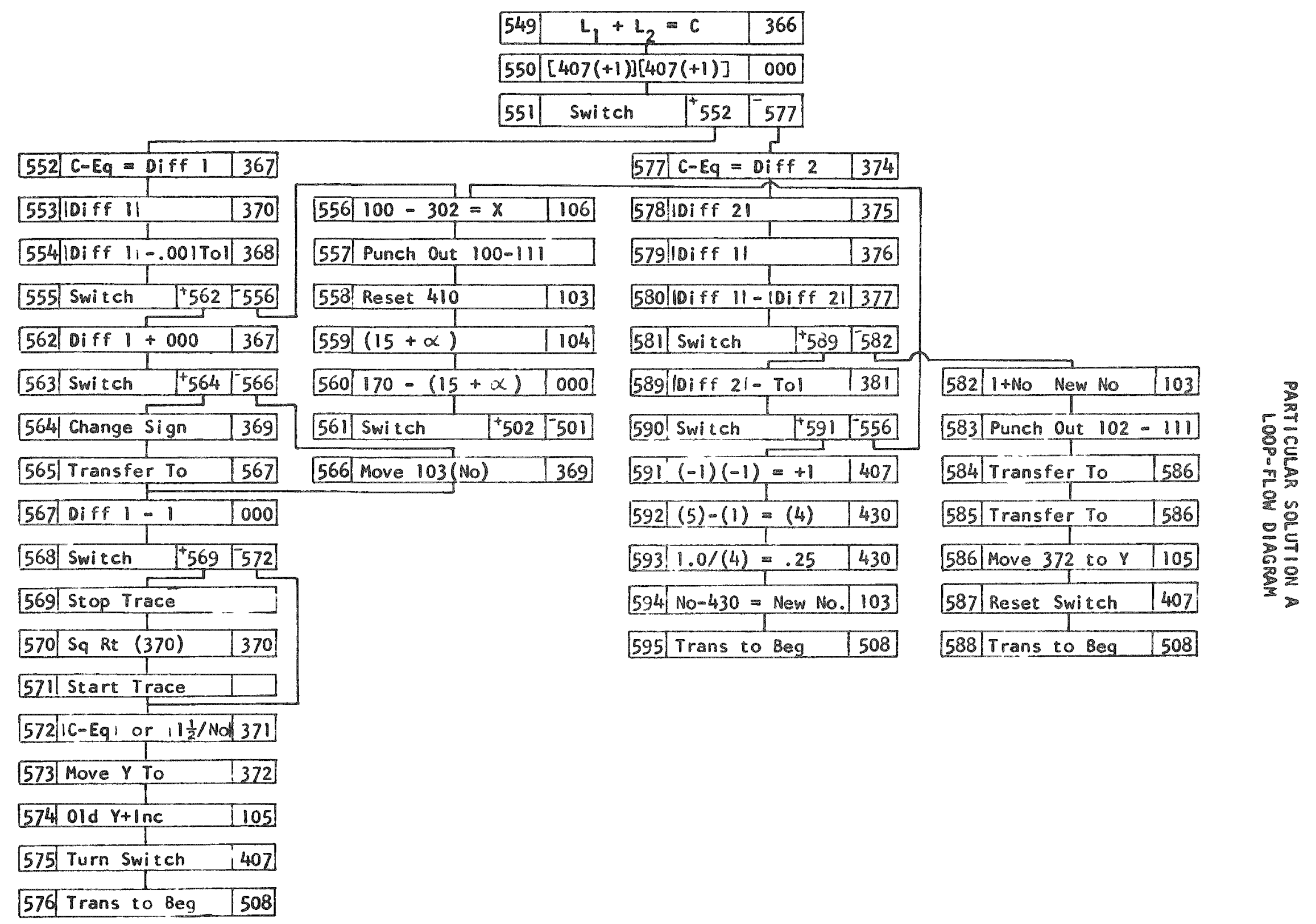




\begin{tabular}{|c|c|c|c|c|c|c|c|}
\hline 464 & 0400400411 & 0400100111 & 0451000000 & 0354104200 & 0353104201 & 0454000000 & \\
\hline 470 & 0450000000 & 4200201202 & 3102102300 & 3000402301 & 3400102302 & 0454000000 & \\
\hline 476 & 1105302303 & 3000000304 & 2301304305 & 0350305306 & 0451000000 & 0454000000 & \\
\hline 482 & 0300306307 & 0450000000 & 2100307308 & 3000000309 & 3105105310 & 0454000000 & \\
\hline 488 & 1310309311 & 2000300312 & 0350312313 & 0451000000 & 0300313107 & 0454000000 & \\
\hline 494 & 0450000000 & 3105202314 & 3000000315 & 2307314316 & 3000000317 & 0454000000 & \\
\hline 500 & 1315310318 & 0451000000 & 0300318319 & 0450000000 & 2101319320 & 0454000000 & 0 \\
\hline 506 & 3320320321 & 1000317322 & 3316320323 & 1200200324 & 3000323325 & 0454000000 & 8 \\
\hline 512 & 2322325326 & 2000300327 & 0350327328 & 0451000000 & 0300328109 & 0454000000 & $\frac{a}{3}$ \\
\hline 513 & 0450000000 & 2403104329 & 4000403329 & 3000408329 & 2102105330 & 0454000000 & 9 \\
\hline 524 & 0451000000 & 0300311331 & 0450000000 & 4330331332 & 3307201333 & 0454000000 & \\
\hline 530 & 3105200334 & 0350326335 & 0451000000 & 0300335336 & 0450000000 & 0454000000 & \\
\hline 536 & 2102333337 & 1000334338 & 4000336339 & 1000332340 & 1000329341 & 0454000000 & 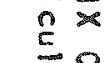 \\
\hline 542 & 3341102108 & 1000107342 & 1000109365 & 1100101366 & 9001332110 & 9001339111 & $\frac{7}{7}$ \\
\hline 548 & 0454000000 & 0454000000 & 34014011407 & 0201552577 & 2366365367 & 0350000370 & $\because$ \\
\hline 554 & 2000403363 & 0201562556 & 9001307106 & 0410100111 & 9001410103 & 1404104104 & $\stackrel{c}{\rightleftarrows}$ \\
\hline 560 & 2405104000 & 0201466465 & 1367406367 & $0 \angle 01564566$ & 5103401369 & 0203000567 & 9 \\
\hline 566 & 2001103369 & 2370401000 & 0201569572 & 0451000000 & 0300370370 & 0450000000 & $\infty$ \\
\hline 572 & 437.4309371 & 9001105372 & 1372371105 & 5401401407 & 0203000472 & 2366365374 & \\
\hline 570 & 0350374375 & 0350367376 & 2376375377 & 0201539532 & 1401103103 & 0410102111 & \\
\hline 504 & 0203000536 & 0203000536 & 9001372105 & 3407407407 & 0203000472 & 2375409381 & \\
\hline 590 & 0201591556 & 3407407407 & 2410401430 & 4401430000 & 2103000103 & 0203000472 & \\
\hline 464 & $\therefore$ & $\therefore$ & $\therefore$ & $\because$ & $\because$ & $*$ & \\
\hline 400 & 5000000049 & 1000000050 & 2250000050 & 1800000052 & 1500000051 & 1700000052 & \\
\hline 406 & 0000000000 & 1000000050 & 3141592650 & 1000000047 & 5000000050 & 0000000000 & \\
\hline
\end{tabular}




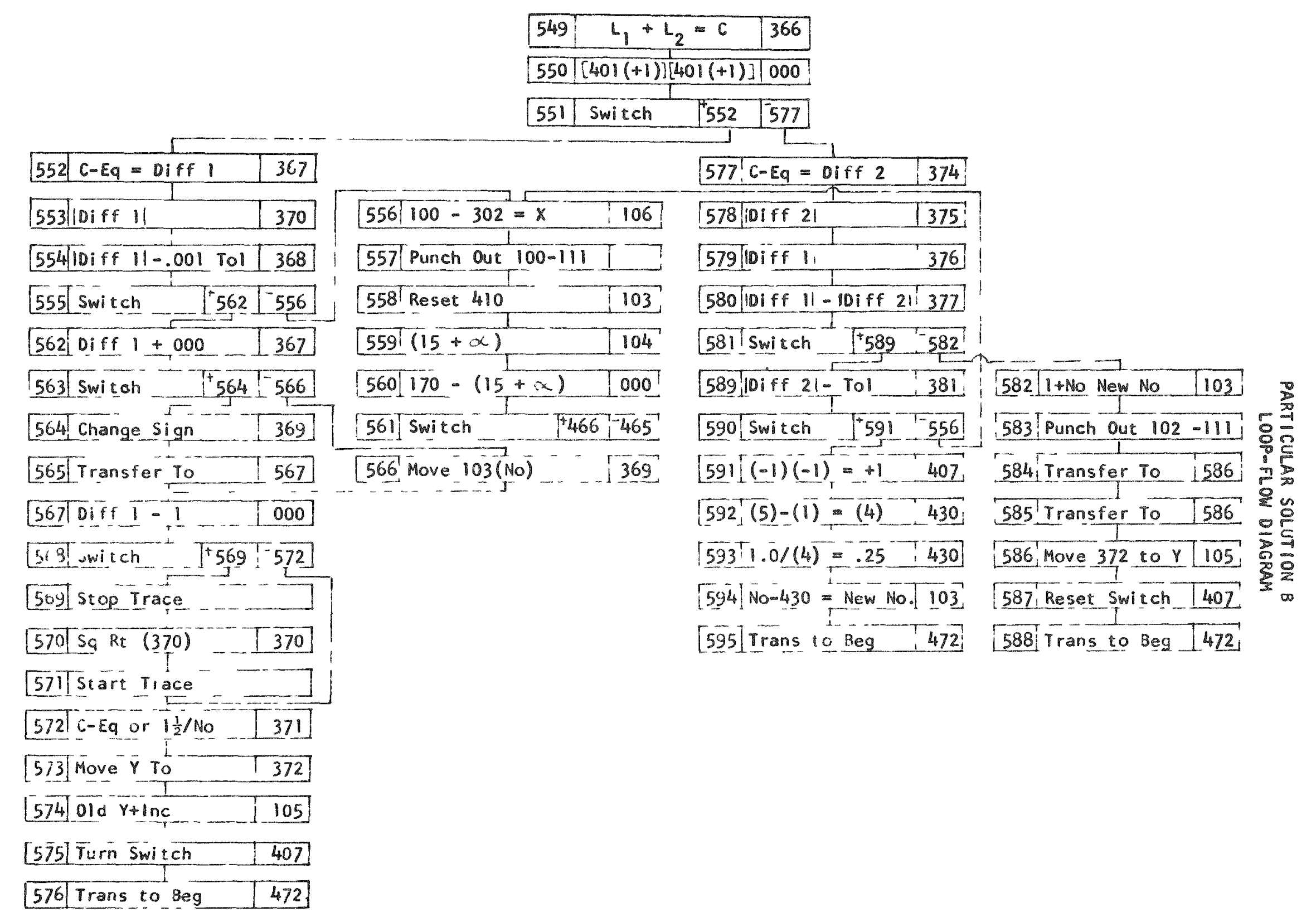




\section{BIBLIOGRAPHY}

1. R. Birrington, Handbook of Mathematical Tables and Formulas, Handbook Publishers, Inc., Sandusky, Ohio (1949).

2. F. Freudenstein, Approximate Synthesis of Four-Bar Linkage, Transactions ASME, 77, 853-861 (1955).

3. F. Freudenstein, Four-Bar Function Generators, Transactions of Fifth Conference on Mechanisms, Purdue, 1958, and Machine Design, Vol.30, No. 24 (1958).

4. R. W. Hamming and R. A. Weiss, General Purpose System for the 650:L2,Bell Telephone Laboratories, Murray Hill, New Jersey.

5. R. S. Hartenberg and J. Denavit, The Fecund Four-Bar, Transactions of Fifth Conference on Mechanisms, Purdue, 1958, and Machine Design, Vol. 31, No. 8 (1959).

6. C. W. Horn and E. J. Crane, Mechanics of Machinery, McGraw-Hill, New York, New York, Third Edition (1948).

7. O. A. Leutwiler, Elements of Machine Design, McGraw-Hill, New York, New York, (1917), Chapter IX, p. 195.

8. V. Maleev, Machine Design, International Textbook Company, Scranton, Pennsylvania (1946), Chapter XI, p. 215-225.

9. A. Vallance and V. Doughtie, Design of Machine Members, McGraw-Hill, New York, New York (1951), Third Edition, Chapter XXI. pp. 384-396.

10. V. M. Wolontis, A Complete Floating-Decimal Interpretive System for the IBM 650 Magnetic Drum Calculator, Bell Telephone Laboratories, Murray Hill, New Jersey, IBM Technical Newsletter No. 11, New York, New York (1956).

11. American Tiger Brand Wire Rope, American Steel and Wire Division of United States Steel, Cleveland, Ohio (1952).

12. Elastic and Thermal Properties of Roebling Aircord, Wire Rope Engineering Bulletin No. 35 103-12, John A. Roebling's Sons Corporation, Trenton, New Jersey (1953). 


\section{ACKNOWLEDGMENT}

The author wishes to express his grateful appreciation to Professor R. S. Hartenberg of the Mechanical Engineering Department for his guidance and inspiration in the preparation of this paper. Professor J. Denavit's generous aid and helpful suggestions are acknowledged with deep thanks. Above all, the author is indebted to the Remote Control Engineering Division of the Argonne National Laboratory for encouragement and cooperation. 